\title{
Epithelial-immune cell interplay in primary Sjögren syndrome salivary gland pathogenesis
}

Gwenny M. Verstappen ${ }^{1,2}$, Sarah Pringle $\mathbb{B}^{1,2}$, Hendrika Bootsma ${ }^{\boxplus}$ and Frans G. M. Kroese

Abstract | In primary Sjögren syndrome (pSS), the function of the salivary glands is often considerably reduced. Multiple innate immune pathways are likely dysregulated in the salivary gland epithelium in pSS, including the nuclear factor-kB pathway, the inflammasome and interferon signalling. The ductal cells of the salivary gland in pSS are characteristically surrounded by a $\mathrm{CD} 4^{+} \mathrm{T}$ cell-rich and $\mathrm{B}$ cell-rich infiltrate, implying a degree of communication between epithelial cells and immune cells. B cell infiltrates within the ducts can initiate the development of lymphoepithelial lesions, including basal ductal cell hyperplasia. Vice versa, the epithelium provides chronic activation signals to the glandular B cell fraction. This continuous stimulation might ultimately drive the development of mucosa-associated lymphoid tissue lymphoma. This Review discusses changes in the cells of the salivary gland epithelium in pSS (including acinar, ductal and progenitor cells), and the proposed interplay of these cells with environmental stimuli and the immune system. Current therapeutic options are insufficient to address both lymphocytic infiltration and salivary gland dysfunction. Successful rescue of salivary gland function in pSS will probably demand a multimodal therapeutic approach and an appreciation of the complicity of the salivary gland epithelium in the development of pSS.

Nearly 100 years ago, Henrik Sjögren described a disease whereby patients had a reduced functionality of the salivary glands (xerostomia) and lacrimal glands (xerophthalmia), with accompanying disturbances of the cornea and the conjunctiva (keratoconjunctivitis sicca) ${ }^{1}$. Sjögren syndrome, named after his work, has since been extensively characterized and is now considered a systemic autoimmune disease. Primary Sjögren syndrome (pSS) typically refers to the occurrence of Sjögren syndrome as the first clinically presenting autoimmune condition in a patient. In terms of clinical presentations, pSS is associated with dryness of the mouth, eyes and vagina, chronic pain and fatigue, and numerous possible extraglandular organ manifestations (including neuropathies, pulmonary manifestations and nephritis) ${ }^{2}$.

pSS is mirrored in pathological and biological analyRheumatology and Clinical Immunology, University of Groningen, University Medical Center Groningen, Groningen, Netherlands.

${ }^{2}$ These authors contributed equally: Gwenny M. Verstappen, Sarah Pringle.

凶e-mail: h.bootsma@umcg.nl https://doi.org/10.1038 s41584-021-00605-2 striated ducts, consist mostly of CD4 $4^{+} \mathrm{T}$ cells and B cells, although other immune cells, including (but not limited to) myeloid dendritic cells, plasmacytoid dendritic cells (pDCs) and follicular dendritic cells, might also be present ${ }^{5,6}$. These infiltrates can develop into ectopic lymphoid structures, even comprising ectopic germinal centres ${ }^{7}$. Particular attention has been paid to the role of (glandular) B cells in pSS pathogenesis. These cells are hyperactive in PSS and responsible for the formation of autoantibodies, hypergammaglobulinaemia, lymphoepithelial lesions (LELs) and pSS-related mucosa-associated lymphoid tissue (MALT) lymphoma ${ }^{8-11}$.

Regarding autoantibodies, anti-SSA/Ro (and to a lesser extent anti-SSB/La) antibodies are present in the majority of patients with $\mathrm{pSS}^{3}$. Serum levels of anti-SSA/Ro and anti-SSB/La antibodies correlate with the number of corresponding plasma cells in the minor salivary glands of patients with pSS, suggesting that salivary glands form an important niche for autoantibody-secreting cells ${ }^{12}$. The SSA/Ro antigen comprises two ribonucleoproteins, Ro52 and Ro60, which are both present in the cytoplasm of all mammalian cells. Although a direct contribution of autoantibodies to exocrine gland dysfunction in humans has not been proven, they have been linked to glandular immune activation ${ }^{13}$. 


\section{Key points}

- Dysregulation of the functional machinery of acini, activation and apoptosis of ductal cells and defects in progenitor cell homeostasis all contribute to salivary gland dysfunction in primary Sjögren syndrome (pSS).

- Unknown trigger(s) in salivary gland epithelial cells might activate innate immune responses and result in adaptive immune responses towards self-antigens, making epithelial cells both mediators and targets of the response.

- Dysregulation of innate immune signalling pathways in salivary gland epithelial cells and consequent pro-inflammatory cytokine production by the epithelium probably contributes to salivary gland dysfunction.

- Direct or indirect interference of autoantibodies with innate immune responses could perpetuate type I interferon activity in salivary gland epithelial cells and immune cells.

- Increased activation of nuclear factor-kB and expression of pro-survival factors, together with enhanced proliferation, might predispose certain intraepithelial $B$ cells to neoplastic changes, promoting mucosa-associated lymphoid lymphoma development.

- The restoration of salivary gland function in patients with pSS might require treatment tailored to glandular pathology and multimodal therapeutic approaches, for example, a combination of immunotherapy and cell therapy.

The fact that autoantibodies, encompassing anti-SSA/Ro antibodies, anti-SSB/La antibodies and rheumatoid factor, can be present years before pSS diagnosis suggests that an additional trigger is needed in the development towards clinical disease ${ }^{14}$. The journey towards impaired function of the salivary glands in pSS, resulting in reduced saliva production and a notable decrease in patient quality of life, is most probably multifactorial and still somewhat enigmatic.

Far from being only a site where infiltrating immune cells assemble, the ductal epithelium has a central role in disease pathogenesis. In this Review, we discuss how interactions between the epithelium and the immune system in pSS contribute to both disease initiation and throughout different stages of disease development in patients with pSS. We focus on new insights into the development of abnormalities in epithelial cells, as well as innate immune signalling and T cell and B cell activation within the salivary glands. All studies cited are based on human samples, unless specifically otherwise stated.

\section{Salivary gland epithelium abnormalities}

A complete discussion of the deterioration of salivary gland function in pSS necessitates comprehension of the foundation of the salivary gland: the epithelium. The salivary gland epithelium comprises several cell types, namely acinar, myoepithelial and ductal cells (FIG. 1 a). Acinar cells produce and secrete either watery or mucous-rich saliva (referred to as serous or mucous acinar cells, respectively). This secretion is facilitated by the contraction of myoepithelial cells that envelope the acinar cell clusters. The secreted saliva is channelled and simultaneously modified through small intercalated ducts into striated ducts (both consisting of basal and luminal cell types), and finally through the larger excretory ducts into the mouth. This architecture can be applied to both the minor and major (parotid, submandibular and sublingual) salivary glands. Although all salivary glands can be affected in pSS, the minor glands of the lower lip (the labial salivary glands (LSGs)) are most often used in diagnosis and research owing to their relative ease of access. Notably, minor salivary glands, including the LSGs, account for less than $10 \%$ of unstimulated whole saliva production ${ }^{15}$. This caveat aside, the literature suggests that the volume of LSG lymphocytic infiltration correlates only weakly with the reduction in salivary gland function in $\mathrm{pSS}^{16,17}$, implying that additional mechanisms or epithelium-specific deficits are probably important in decreased salivary gland function in pSS.

\section{Changes in acinar cells in pSS}

Acinar cells are the saliva-producing workhorses of the salivary glands, controlling both the volume and protein content of saliva. All the acinar cells in the parotid gland, the major gland responsible for saliva production after stimulation, are serous cells. The action of chewing or exposure of taste receptors to acidic substances stimulates these cells to secrete the digestive enzyme $\alpha$-amylase. pSS is associated with a decrease in the amount and activity of $\alpha$-amylase, strongly implying that serous acinar cells have a less than optimal function in $\mathrm{pSS}^{18-20}$. Despite a notable reduction in saliva production in $\mathrm{pSS}$, the number and gross morphology of acinar cells in both the LSGs and the parotid salivary gland often appears normal, implying that, even if defective, acinar cells remain viable in pSS. In support of this idea, various data show that the levels of FAS-FAS ligand (FASL)-induced apoptosis in acinar cells is low in patients with pSS, although the levels are higher than those of control populations (such as healthy individuals $)^{21-23}$. However, data from studies in mice suggest that TNF is capable of inducing apoptosis of major salivary gland acinar cells; notably, acinar cells from the NOD mouse, a model of pSS, are more likely to undergo TNF-induced apoptosis than cells from age-matched $\mathrm{BALB} / \mathrm{c}$ (control) mice ${ }^{24}$. Conversely, treatment of human LSG acinar cells with TNF and IFN $\gamma$ seems to induce the expression of the anti-apoptotic genes ATF6 and $E R A D^{25}$. To complicate the situation further, levels of sex hormones might also affect acinar cell apoptosis ${ }^{26}$. Taken together, no firm conclusions can be drawn from the available data regarding the degree of acinar cell apoptosis that occurs in the salivary glands in pSS.

The secretion of saliva by acinar cells begins with the engagement of the muscarinic 3 receptors on acinar cells by muscarinic neurotransmitters such as acetyl choline. Downstream of this event, an increase in cytosolic levels of $\mathrm{Ca}^{2+}$ in these cells occurs, originating from both outside the cells and from intracellular internal endoplasmic reticulum stores ${ }^{27}$. The presence of autoantibodies directed against extracellular loops of the muscarinic 3 receptor implies that these very first stages of secretion might already be disturbed in pSS, or at least targeted by the immune system ${ }^{28}$ (FIG. 1 b). Muscarinic receptor binding and the subsequent increase in cytosolic $\mathrm{Ca}^{2+}$ culminates in inositol 1,4,5-trisphosphate receptor (IP3R) signalling, via the secretory machinery components phosphatidylinositol 4,5-bisphosphate (PIP2) and synaptotagmin 1 . Notably, the levels of IP3R and the expression of synaptotagmin 1 are decreased in salivary gland acinar cells of patients with pSS compared with 
in healthy individual ${ }^{29,30}$. Furthermore, both PIP2 and synaptotagmin 1 seem to localize to the acinar cell basolateral membrane in pSS rather than to the apical membrane, suggesting at least dysfunction of the secretory machinery ${ }^{30}$. Hence, various critical components of the secretory machinery in acinar are dysregulated in pSS.

Another mechanism proposed to interfere with the calcium signalling phase of saliva production in pSS a Salivary gland

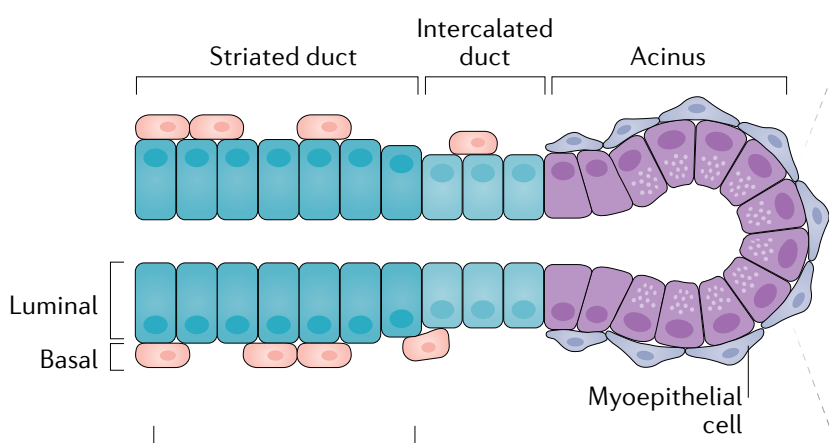

c Ductal cells

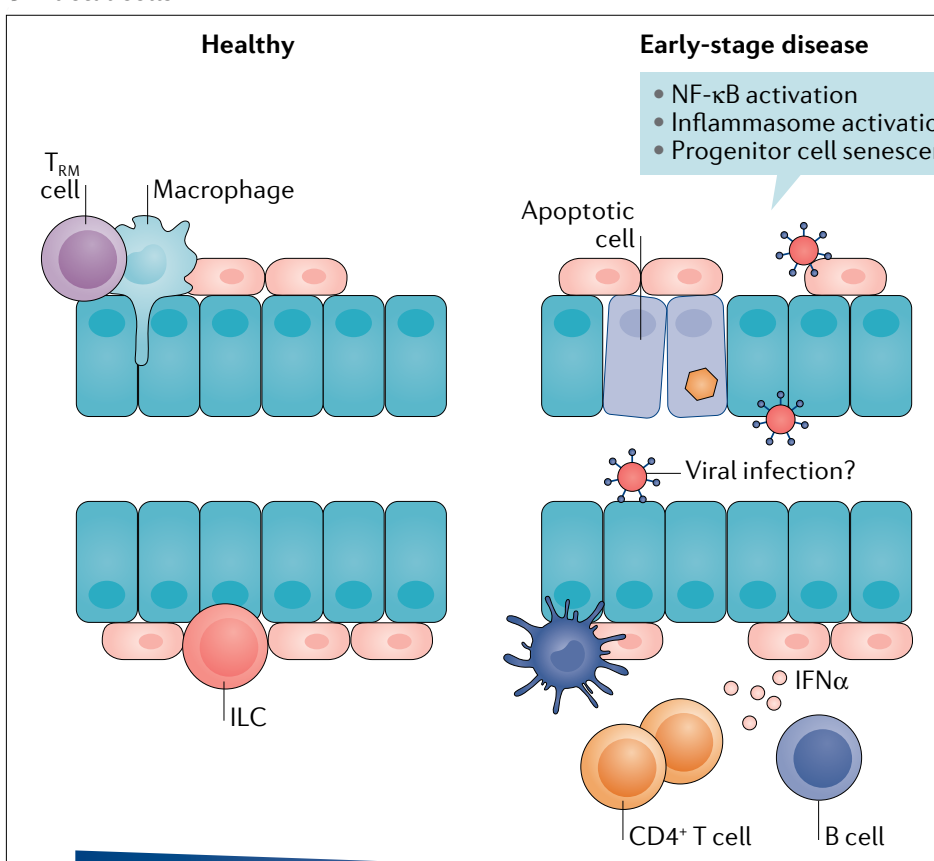

b Acinar cells

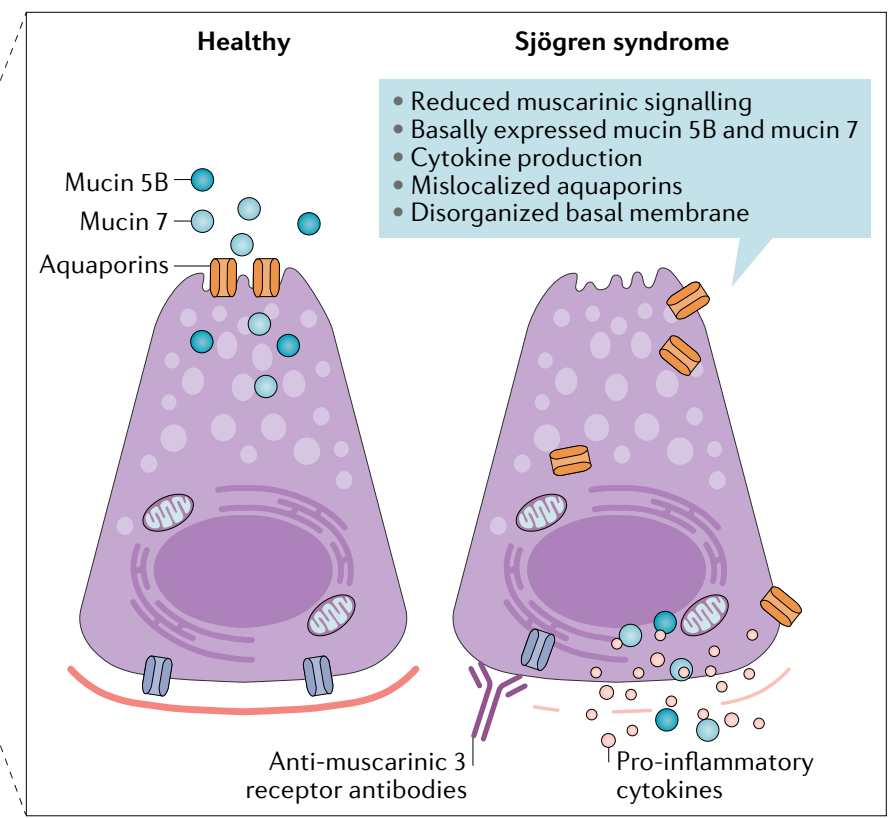

Saliva production

Fig. 1 | The salivary gland epithelium in health and in pSS. a | The salivary gland epithelium is made up of several cell types, including acinar cells (that cluster to form the acinus), ductal cells (consisting of basal and luminal cell types) that form the striated and intercalated ducts, myoepithelial cells and progenitor cells. Saliva is produced by acinar cells and secreted upon myoepithelial cell contraction. Saliva is then channelled and modified through the intercalated and striated ducts and flows via larger excretory ducts into the mouth. $\mathbf{b}$ | Acinar cells contain multiple defects in primary Sjögren syndrome (pSS). c| A number of pathogenic events could take place in the ductal epithelium during pSS development. In a healthy situation, several immune cells (for example, macrophages, innate lymphoid cells (ILCs) and tissue resident memory $\left(T_{R M}\right)$ cells) are present for immune surveillance to enable a fast response to injury or infection. In pSS, an unknown trigger (for example, viral infection or tissue damage) might cause activation of innate immune pathways, epithelial cell apoptosis and senescence, which is exacerbated in more severe stages of disease. Late-stage disease is characterized by chronic antigen exposure, local production of autoantibodies, accumulation of $\mathrm{CD}^{+}$ T cells and B cells, complete loss of progenitor cells and the formation of lymphoepithelial lesions. These lesions are characterized by basal cell hyperplasia and the presence of intraepithelial lymphocytes. 
involves the microRNA miR-142-3p. This microRNA is present in secreted exosomes derived from infiltrating $\mathrm{T}$ cells in the glands and is transferred to acinar cells. miR-142-3p targets important components of intracellular $\mathrm{Ca}^{2+}$ signalling, ultimately resulting in decreased saliva production ${ }^{31}$. In healthy scenarios, successful $\mathrm{Ca}^{2+}$ signalling results in the activation of aquaporin (AQP) water channels, and water is transported out of the apical membrane of acinar cells. Notably, the expression of the various $A Q P s$ is increased (AQP5) or decreased (AQP1, AQP3 and AQP5) in patients with pSS compared with healthy individuals, and the ability of these channels to respond to muscarinic stimuli are decreased compared with individuals without $\mathrm{pSS}^{32,33}$.

The function of saliva depends not only on water secretion but also on its protein content. Mucins, produced by the salivary gland mucous acinar cells, provide essential lubrication to facilitate swallowing, and are secreted via the apical pole of acinar cells ${ }^{34}$. Mucous-producing acinar cells are found in the LSGs, as well as in the submandibular and sublingual major salivary glands ${ }^{34}$. In pSS, the salivary mucin components MUC5B and MUC7 are found outside the basal pole of LSG mucous acinar cells ${ }^{35,36}$. Interestingly, MUC5B and MUC7 are capable of Toll-like receptor 4 (TLR4)-mediated autocrine stimulation of CXCL8, TNF, IFN $\alpha$, IFN $\beta$, IL- 6 and IL- $1 \beta$ production by LSG acinar cells ${ }^{36}$. Consequently, basally mislocalized mucins might contribute to glandular inflammation. However, the direction of causality between mucin disruption and acinar cell inflammation remains to be clarified, as does the relevance of mucin disruption in the larger, non-mucin-producing parotid salivary gland. The basal lamina, which is normally strictly localized to the basal pole of acinar cells to provide anchorage and polarization, is also disorganized in the salivary glands in $\mathrm{pSS}^{37}$. This change might contribute to the secretion of mucins at the wrong cellular pole, although further evidence is needed to support this idea. Intriguing further data suggest that the cytoplasm and endoplasmic reticulum are overloaded with a different mucin, MUC1, in LSG acinar cells in pSS, which might cause cellular stress and potentially increase the likelihood of apoptosis ${ }^{35,36,38}$. In a separate study, incubation of LSG acinar cells with TNF or IFN $\gamma$ triggered both increased nuclear factor $-\kappa \mathrm{B}(\mathrm{NF}-\kappa \mathrm{B})$ activity and overexpression and aberrant localization of MUC1 ( $\mathrm{REF}^{38}$ ), implying that the aberrant distribution of mucins might be a consequence of the inflammatory environment in the salivary glands in pSS, potentially culminating in cellular stress and cell death.

pSS is associated with the presence of autoantibodies, most often with antibodies directed against SSA/Ro proteins. However, autoantibodies directed against the acinar cell-associated proteins parotid secretory protein, salivary protein 1 and carbonic anhydrase 6 have also been reported in some patients with pSS, in addition to those antibodies against the muscarinic 3 receptor mentioned above ${ }^{39-41}$. These findings open up debate as to whether acinar-specific autoantibodies have a potential role in the induction of cell death in acinar cells, or whether these antibodies are a downstream consequence of that process.
Acinar cells might thus contribute to the expression of pro-inflammatory cytokines in pSS and are grossly dysregulated in terms of the functional machinery necessary for saliva production (FIG. 1 b). The extent of apoptosis of the cells, and its relation to the development of salivary gland disease, requires further clarification. Despite the observed abnormalities in acinar cells of patients with pSS, these abnormalities do not cumulatively result in appreciable numbers of immune cells surrounding the acini, as the infiltrating cells accumulate mostly around the striated ducts. However, it remains possible that cytokines produced by periductal infiltrates affect acinar cells. Furthermore, the potentially pathogenic role of the small number of interstitial immune cells and immune cells located within the acini (for example, $\mathrm{CD} 8^{+} \mathrm{T}$ cells) ${ }^{37}$ needs further investigation.

\section{Changes in ductal cells in pSS}

Complementing the acinar cells responsible for making saliva are the ductal cells. Aside from the channelling of saliva into the mouth, ductal cells are also responsible for the extraction of sodium from, and the addition of potassium to, the saliva. This process, mediated via calcium-activated sodium and potassium channels, culminates in attainment of the hypotonic sodium and potassium concentrations necessary for the slightly acidic antimicrobial functions of saliva, and for the prevention of mineral loss from dental hard tissues ${ }^{42}$. In patients with pSS, the concentrations of sodium and chloride in the saliva are higher than in healthy individuals, potentially owing to a reduction in ion resorption by ductal cells and/or because the volume of water secreted from acinar cells is reduced ${ }^{19,20,43,44}$. The investigation of the role of ductal cells in pSS has centred historically around the striated ducts in histology-based studies or in vitro culture systems of salivary gland epithelial cells (SGECs). Although cultured SGECs might represent ductal cells in general (that is, both striated and intercalated ductal cells), whether they represent striated duct cells specifically has never been proven ${ }^{45}$. For the purpose of this Review, however, we will treat SGEC cultures as a model for striated duct cells, referred to as SGECs (to mean LSG-derived SGECs) throughout unless mentioned otherwise.

SGECs from patients with Sjögren syndrome respond aberrantly to extrinsic stimuli. For example, SGECs from patients with pSS are more sensitive to FAS/FASL-mediated apoptosis in the presence of TNF and IFN $\gamma$ than SGECs from healthy individuals ${ }^{46,47}$. These cells are also more susceptible to other mechanisms of programmed cell death, such as IFN $\gamma$-induced or poly (I:C)-induced anoikis (that is, apoptosis due to loss of attachment to the basal membrane $)^{48}$. However, data from the literature suggest that striated duct cells $^{22,49}$ and SGECs ${ }^{50}$ are both resistant and susceptible to apoptosis.

In addition to disturbed apoptosis, SGECs express various TLRs (TLR1, TLR2, TLR3, TLR4 and TLR7) and other pattern recognition receptors (PRRs), implying that these cells have an ability to process pathogen-associated molecular patterns (PAMPs) and danger-associated molecular patterns (DAMPs). 
Furthermore, TLR3 activation can stimulate the expression of pSS-associated autoantigens SSA/Ro60, SSA/Ro52 and SSB/La by SGECs ${ }^{51}$. SGECs can also express receptors for cytokines, including receptors for type I interferons and $\mathrm{TNF}^{52-54}$. The chemokine receptor CXCR3 might function as a scavenging receptor in the healthy salivary gland, preventing a build-up of surplus pro-inflammatory chemokines such as CXCL9, CXCL10 and CXCL11. In pSS, the function of this receptor is thought to be impaired in the ductal cells; indeed, in SGECs from patients with Sjögren syndrome, intracellular levels of CXCL10 are reduced compared with SGECs from healthy individuals, which is presumed to be a consequence of impaired CXCR3 functionality permitting the accumulation of these chemokines ${ }^{55}$. In addition to responding aberrantly to extrinsic stimuli, striated duct cells ${ }^{56,57}$ and SGECs ${ }^{52,58}$ from patients with Sjögren syndrome also express many cytokines and chemokines (for example, IL-1, IL-6, IL-7, IL-18, TNF, B cell-activating factor (BAFF), CXCL10, CXCL12 and CXCL13) at higher levels than those observed in healthy individuals. Thus, striated ducts and their presumed in vitro counterpart SGECs are capable of regulating the immune response (as discussed in more detail in the section on epithelial cell-lymphocyte crosstalk).

Considering the involvement of striated duct cells in, for example, LELs, the NF- $\mathrm{kB}$ pathway and inflammasome activation (as discussed in detail in later sections), we would argue that the role of striated duct cells in the development of pSS pathology cannot be understated. The further roles of smaller, intercalated ducts remain until this point less well understood, and will require further investigation.

\section{Salivary gland homeostasis disruption}

Mouse studies have shown that a small number of immune cells, including but potentially not limited to tissue-resident memory $\mathrm{T}\left(\mathrm{T}_{\mathrm{RM}}\right)$ cells, macrophages, group 1 innate lymphoid cells (ILC1s), natural killer cells and dendritic cells, patrol the salivary glands, scanning for hallmarks of infection and/or epithelial cell damage ${ }^{59,60}$ (FIG. 1c). $\mathrm{T}_{\mathrm{RM}}$ cells and macrophages, in particular, have been identified in close association with the mouse acinar epithelium ${ }^{60}$. In patients with pSS, this homeostatic surveillance system seems to be disturbed, and the salivary gland immune landscape is unbalanced owing to an infiltration of mainly CD4 ${ }^{+} \mathrm{T}$ and $\mathrm{B}$ cells as well as, in lower abundance, pDCs and other immune cells ${ }^{9}$. Besides their immune function, these infiltrating cells can affect salivary gland homeostasis in multiple ways, including crosstalk with the salivary gland epithelium (which will be discussed in more detail in the section on epithelial cell-lymphocyte crosstalk).

In normal salivary gland homeostasis, the aforementioned immune cell sentinels are complemented by salivary gland progenitor cells (SGPCs). SGPCs proliferate and differentiate into fresh acinar and ductal cells, to replenish damaged cells and cells reaching the end of their lifespan ${ }^{61-64}$. In the major salivary glands, the ductal compartment (both the striated and intercalated ducts) has been proposed to house SGPCs, although progenitor cells might also be present in the acinar compartment ${ }^{61,65-67}$. These progenitor cells can be studied in vitro through organoid cultures ${ }^{61,65,68}$. The number of SGPCs is much lower in patients with pSS than in healthy salivary glands, and the few that remain have a lower differentiation capacity ${ }^{68}$. One explanation for this finding is that progenitor cells residing in the basal layer of the parotid gland striated ducts become senescent prematurely in pSS, as a result of the mitotic effects of pro-inflammatory cytokines ${ }^{68}$. The telomeres of SGPCs from patients with $\mathrm{pSS}$ are shorter, suggesting that some SGPCs have indeed undergone replicative senescence ${ }^{68}$. In one study, the degree of senescence of cells located in the basal layer of the striated ducts (where progenitor cells probably reside), as inferred from the expression of the senescence marker p16, correlated with the production of saliva by the parotid salivary gland, the extent of $\mathrm{CD} 45^{+}$cell infiltration and the ultrasound score ${ }^{69}$. The expression of $\mathrm{p} 16$ by all acinar and ductal cells combined also correlated with saliva production and $\mathrm{CD} 45^{+}$cell infiltration, but to a lesser extent ${ }^{69}$. Senescent cells in general have a senescence-associated secretory phenotype (SASP), consisting of the expression of a panel of pro-inflammatory cytokines (including IL-1 $\alpha$, IL- $1 \beta$, IL-6, IL-7, IL-13, IL-15, TGF $\beta$, GM-CSF and TNF), chemokines (including IL-8, GRO $\alpha$, GRO $\beta$, CCL2, CCL3, CCL5, CCL16, CCL26 and CCL20), growth factors (including HGF and FGF), matrix metalloproteases and proteases ${ }^{70-72}$. Most interestingly and potentially detrimentally, this SASP enables the active spreading of senescence directly to neighbouring cells $\mathrm{s}^{72}$. Therefore, senescent cells might not only reduce the ability of the salivary gland to function, by disabling a potential progenitor cell population, but also augment inflammation and disease progression. Coupled with this effect is the strange persistence of functionally defective acinar cells, whose clearance would otherwise presumably trigger replacement with fresh counterparts by SGPCs, a curious dynamic that requires more investigation.

Of further interest, disruption of salivary gland homeostasis also occurs in patients undergoing immune checkpoint inhibitor (ICI) therapy for the treatment of cancer. Approximately 5\% of ICI-treated patients will experience some form of salivary gland dysfunction ${ }^{73-76}$. Among these patents, $60 \%$ will progress to technically fulfil the ACR-EULAR 2016 criteria for $\mathrm{pSS}^{3}$, owing to the presence of sicca symptoms, immune foci in the salivary glands and/or autoantibody positivity ${ }^{73-76}$. The potential mechanism of ICI-induced salivary gland dysfunction is highlighted in BOX 1 .

\section{Virus-epithelial cell interactions}

Microorganisms are implicated as a potential trigger in the development of pSS. Activation of TLRs that recognize components of bacteria (such as TLR1, TLR2 and TLR4) or viruses (such as TLR3, TLR7 and TLR9) on salivary gland ductal cells, for example, might represent a first step in the initiation of inflammation in the salivary gland in the early stages of disease. However, evidence that conclusively demonstrates the contribution of specific bacteria to salivary gland dysfunction in pSS is lacking ${ }^{77-81}$. Indeed, the most likely hypothesis is that alterations in the bacteriome in the oral cavity 


\section{Box 1 | Salivary gland dysfunction following checkpoint inhibition}

Both the major and minor salivary glands contain a T cell-rich inflammatory infiltrate following immune checkpoint inhibitor $(\mathrm{ICl})$ use, but the glands do not resemble classical salivary glands of patients with pSS on the infiltration level ${ }^{74,203}$. Some evidence suggests that $\mathrm{ICl}$ therapy induces a considerable shift in the organization of the parenchyma (specifically, a loss of typical saliva-producing acinar cells) ${ }^{203}$. The mechanism underpinning this effect is as yet unclear, but might encompass acinar cell death followed by aberrant salivary gland progenitor cell compensation, or increased plasticity of salivary gland epithelial cell types. This plasticity could be induced, for example, by the presence of the type II interferon signature associated with cytotoxic T cell activation and checkpoint inhibitor therapy (as opposed to the type I interferon signature most commonly associated with classical pSS), and might explain the notably different morphology observed ${ }^{204}$. Although presenting potentially with a different phenotype to pSS, deciphering how this epithelial skewing occurs will probably shed light on the mechanism underpinning salivary gland dynamics in general.

represent a consequence, rather than a cause, of salivary gland dysfunction in $\mathrm{pSS}^{82}$. Nevertheless, the triggering of specific TLRs and other (cytosolic) PPRs on SGECs by viral material might result in type I interferon production, and conceivably contribute to the well-known type I interferon signature associated with pSS. Although intrinsic and other extrinsic triggers might also be responsible for interferon production by epithelial cells (as discussed in the later section on interferon pathways and as reviewed elsewhere ${ }^{83}$ ), this common feature of pSS suggests the presence of an initial immune response against viral infection.

To date, infection with three different viruses has been associated with the development of pSS. First, some data suggest that past infection with hepatitis $C$ virus $(\mathrm{HCV})$ is associated with the development of pSS, with estimates suggesting that approximately $14 \%$ of patients with pSS test positive for antibodies against HCV in certain pSS populations ${ }^{84-86}$. However, it should be noted that HCV infection (latent or active) is an exclusion criterion in the 2016 ACR-EULAR classification criteria for pSS and debate exists as to whether this patient subgroup truly represents pSS or a Sjögren syndrome-like condition, especially as HCV infection rates vary widely geographically ${ }^{86}$. Second, chronic infection with human T cell lymphotropic virus type 1 (HTLV1) has also been associated with low-grade salivary gland damage in pSS and increased serum concentrations of TNF and IFN $\gamma$, although this virus is not necessarily associated with pSS development ${ }^{87,88}$. Patients with sicca syndrome and HTLV1 antibody serum positivity, for example, do not tend to have anti-SSA autoantibodies ${ }^{87,88}$. Third, various evidence points to an association between Epstein-Barr virus (EBV) and pSS, although it should be noted that this virus is very common and present in up to $95 \%$ of the general population ${ }^{89}$. The EBV remains latent in resting memory $B$ cells and requires $B$ cell stimulation and plasma cell differentiation for lytic replication ${ }^{89-91}$. This ability to remain dormant in memory B cells means that the virus poses a persistent threat. EBV DNA has been detected at increased levels in the salivary glands of patients with pSS compared with healthy individuals, with Ro52-reactive perifollicular plasma cells being frequently infected ${ }^{92,93}$. Furthermore, patients who were also positive for anti-SSA and/or anti-SSB antibodies had higher titres of IgG antibodies against the EBV early antigen than those patients without anti-SSA and anti-SSB antibodies ${ }^{91}$.

EBV is capable of directly infecting epithelial cells; in these cells, the EBV glycoprotein BMRF2 mediates transport of the virus to the basolateral membrane and seems to facilitate spreading of progeny virions ${ }^{94}$. In one study, levels of the EBV-derived microRNA ebv-miR-BART13-3p were increased in the salivary glands of patients with pSS compared with healthy individuals ${ }^{95}$. Interestingly, ebv-miR-BART13-3p was suggested to downregulate the expression of stromal interaction molecule 1 (STIM1), a component of the acinar cell secretory machinery, providing a plausible link between EBV and saliva production ${ }^{95}$. This microRNA can transfer between cells, such as between $B$ cells (the preferred target cells of EBV) and SGECs, via microvesicles ${ }^{95}$. Notably, the EBV protein EpsteinBarr nuclear antigen 2 (EBNA2) has a marked degree of protein sequence similarity to Ro60 autoantigens and likewise the protein sequences of Epstein-Barr virus (EBV)-encoded RNA 1 (EBER1) and EBER2 are strikingly similar to La autoantigens ${ }^{96,97}$. Furthermore, antibodies to Ro60 can cross-react with EBNA1 $\left(\right.$ REF. ${ }^{98}$ ), suggesting that molecular mimicry might trigger immune system activation to self-antigens in pSS. However, no correlation has been found between EBV reactivation periods and the development of pSS symptoms ${ }^{96}$; furthermore, the molecular mimicry hypothesis does not explain why such a common infection as EBV results in pSS development in only a small proportion of these individuals ${ }^{89}$.

How viral infections might contribute to $\mathrm{pSS}$ remains unclear. In addition to the often touted classical hypotheses, including molecular mimicry or enhanced apoptosis of epithelial cells, evidence would also suggest that viruses are capable of inducing epigenetic changes in epithelial cells ${ }^{99}$, an exciting new interaction that remains to be investigated in pSS. Virus-induced epigenetic changes might, for example, repress the expression of pro-apoptotic genes. Impaired viral clearance as a mechanism for pSS development has also been inferred from the presence of a less efficient splice variant of the classical type I interferon downstream mediator OAS1 in patients with $\mathrm{pSS}^{100,101}$.

With respect to SARS-CoV-2 viral infections, it is worth considering that a potential pool of patients with sicca complaints might be emerging. The involvement of the salivary gland as a reservoir of this virus has been proposed, following the identification of the ACE2 receptor (an entry receptor for SARS-CoV-2) on $\mathrm{SGECs}^{102,103}$. Close monitoring of this patient pool over the coming years might provide crucial evidence regarding the role of viral infections in the triggering of sicca symptoms and possibly also in the triggering of pSS.

\section{Innate immune function of the epithelium}

As discussed in the previous sections, the salivary gland epithelium fulfils innate immune functions that are mainly mediated by the expression of PRRs (for example, TLRs) $)^{53,54}$ and the secretion of cytokines. In this section, we discuss the different innate immunological pathways that contribute to dysfunction of the salivary 
gland epithelium in pSS. Although the initial events that cause innate immune activation in the salivary gland epithelium remain to be identified, several possibilities have been raised. These include the involvement of exogenous antigens (for example, PAMPs from ineffectively cleared viruses) or aberrant expression of endogenous factors (for example, retroelements) that stimulate innate immune responses. Another possibility is that these responses are triggered by DAMPs because of inefficient removal of epithelial cell debris. Interestingly, a patient's genetic background might predispose them to impaired clearance of cell debris. The genotype and copy gene number of the complement component $\mathrm{C} 4$ has a high sex bias and has been linked to pSS susceptibility ${ }^{104}$. The lower gene copy number and expression of C4A reported for women that increase the risk of SLE or pSS might reduce the capacity of the immune system to clear cell debris, thereby prolonging exposure of intracellular proteins to the immune system ${ }^{104}$. However, data on the relationship between the $\mathrm{C} 4$ genotype and salivary gland pathology are not yet available.

\section{NF- $\kappa B$ signalling}

The NF- $\kappa \mathrm{B}$ family is a group of transcription factors capable of activating an array of inflammatory downstream targets, including pro-inflammatory cytokines ${ }^{105}$. The canonical NF- $\kappa B$ pathway is activated by binding of PAMPs to the TLRs and by pro-inflammatory cytokines themselves binding to their respective receptors ${ }^{105}$. Engagement of TLR and cytokine receptors triggers activity of the I $\mathrm{BB}$ kinase complex, culminating in

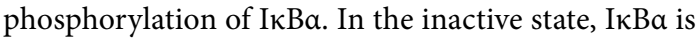
in complex with canonical NF- $\kappa \mathrm{B}$ members RelA and p50, whereas phosphorylation of I $\mathrm{B}$ Ba results in degradation of this inhibitor, enabling the release of the RelA-p50 heterodimer and its subsequent translocation to the nucleus, where the dimer activates target gene transcription ${ }^{105}$. Studies have reported NF- $\kappa B$ activity in the epithelial cells of the salivary glands of patients with $\mathrm{pSS}$, reflected by the expression of NF- $\mathrm{KB}$ downstream target genes encoding cytokines such as IL- $1 \alpha$, IL- 6 and $\mathrm{TNF}^{57}$. NF- $\mathrm{kB}$ is also important for the regulation of cell-cell interactions and is capable of disrupting tight junction integrity ${ }^{106}$. Mutations that result in overactivity of the NF- $\kappa \mathrm{B}$ pathway have been reported in patients with pSS: for example, mutations in genes encoding $\mathrm{I} \kappa \mathrm{Ba}$ or the inhibitor TNFa-induced protein 3 (TNFAIP3; also known as A20) $)^{107-109}$. Interestingly, in mice, constitutive activation of the NF- $\kappa$ B pathway via knockout of TNFAIP3 in cytokeratin 14-expressing epithelial cells (including those cells of the striated duct) is sufficient to result in reduced saliva production and infiltration of a $\mathrm{T}$ cell-rich infiltrate into the salivary glands ${ }^{110}$. This finding emphasizes the role of epithelial cells and the NF- $\kappa \mathrm{B}$ pathway in pSS development, and the apparent ability of activated epithelial cells to recruit immune cells.

\section{The inflammasome}

The inflammasome is an intracellular complex of oligomers that detect and respond to DAMPs and PAMPs to incite inflammation, functioning as an important innate immune system receptor and sensor. Inflammasomes require priming via classical innate immune activation pathways, such as the microbe-activated TLR pathway ${ }^{111}$. Subsequent to this signal, a second activation signal of inflammasome components via stimuli such as lysosomal disruption, reactive oxygen species production and release of oxidized mitochondrial DNA or microbial nucleic acids is required ${ }^{111}$. Inflammasomes can be broadly divided into four types: the absent in melanoma 2 (AIM2) inflammasome, the NOD-, LRR- and pyrin domain-containing protein 1 (NLRP1) inflammasome, the NLRP3 inflammasome and the NLRP4 inflammasome. Inflammasome activation ultimately facilitates processing of pre-formed pro-inflammatory cytokines such as pro-IL- $1 \beta$ and pro-IL-18 into their final active forms. Stimulation of the AIM2 inflammasome occurs following binding by cytosolic free DNA (cfDNA) of viral, bacterial or mammalian origin, but not by other triggers ${ }^{112}$. Some data suggest that the AIM2 inflammasome is highly active in SGECs from patients with pSS, which could be because of defective functioning of DNase 1 resulting in the accumulation of $\mathrm{cfDNA}^{113}$. Patients with pSS and MALT lymphomas, and those patients with pSS judged to be at a high risk of developing MALT lymphomas, have high serum levels of cfDNA and extranuclear DNA accumulations in salivary gland tissue, mostly localized between the striated ducts and lymphocytic infiltrates ${ }^{114}$. This extracellular DNA, if transported into striated duct cells, might be an important stimulus for the AIM2 inflammasome.

Oligomerization of NRLP1, NRLP3 or NRLP4 results from upregulation of NRLP transcription following signals induced by cfDNA, as is described for AIM2, as well as signals induced by a panoply of DAMPs, PAMPs and other triggers, such as reactive oxygen species, oxidized mitochondrial DNA and lysosomal disruption. Various data suggest that the salivary glands of patients with pSS express higher levels of NLRP3 than healthy individuals, and P2X7, a component of the NRLP3 machinery, is also upregulated in the salivary gland tissue of patients with $\mathrm{pSS}^{114,115}$. However, which specific cell types express the upregulated NRLP3 is unclear, as indeed is the expression of the NRLP1 and NRLP4 inflammasomes in $\mathrm{pSS}^{115}$. However, although perhaps less well-understood than the role of the TLR and NF- $\kappa$ B systems, a central role for the inflammasome in pSS is emerging. Mirroring the NF- $\kappa$ B pathway, the activity of the inflammasome in the salivary gland epithelium reinforces the role of the epithelium, and its crosstalk with the immune system, in pSS. The upregulated inflammasome might contribute to the sustained glandular inflammatory process in pSS, and represents a potential alternative therapeutic target.

\section{Interferon pathways}

Important signalling pathways that contribute to the disruption of the salivary gland epithelium in pSS involve interferons. The interferon family consists of type I (IFNa and IFN $\beta$ ), type II (IFN $\gamma$ ) and type III (IFN $\lambda$ ) interferons, which have distinct as well as common functions. Interferons stimulate a wide variety of genes important in innate and adaptive immune responses ${ }^{116}$. In particular, type I interferons create an anti-viral state by promoting immune responses to viruses ${ }^{117}$. The important role of 
interferons in the pathogenesis of pSS is reflected by the elevated transcript levels and altered epigenetic regulation of interferon-stimulated genes (ISGs) in both the blood and salivary gland tissue of patients ${ }^{118-120}$. These ISGs are upregulated in both SGECs and striated ducts, in addition to in immune cells ${ }^{121,122}$, together accounting for the interferon signature of the glands. Indeed, both type I and type II interferon-induced proteins (IFN-induced protein with tetratricopeptide repeats 3 (IFIT3) and guanylate-binding protein 2 (GBP2), respectively) are expressed in ductal epithelial cells, whereas infiltrating immune cells mainly expressed GBP2 (REF. ${ }^{122}$ ). In the following subsections, we discuss both the pathways that result in interferon production (for example, PRR signalling and the overexpression of endogenous retroelements), and the pathways that result from stimulation by interferon (for example, pro-inflammatory cytokine production) in the salivary glands.

Type I interferons. pDCs are a potent source of IFNa within the inflamed salivary gland ${ }^{6}$. Activated pDCs are able to migrate to the salivary glands in response to chemokines such as CXCL12, CXCR3 ligands and CCR5 ligands ${ }^{123,124}$. Within the glands, type I interferon production by $\mathrm{pDCs}$ can be sustained in the presence of TLR7 ligands, TLR9 ligands and immune complexes of autoantibodies and autoantigens that contain TLR7 ligands in the form of autoantigen-associated RNA ${ }^{125}$. Although a strong correlation exists between the presence of Ro/La autoantibodies and the expression of ISGs in the blood and tissue of patients with pSS, the sequence of appearance of these features and their contribution to dysfunction of the salivary gland epithelium need further investigation.

In addition to pDCs, epithelial cells themselves can produce type I interferon after stimulation via PRRs, as demonstrated, for example, in studies of mice and of a human submandibular gland cell line $\mathrm{e}^{36,126}$. Furthermore, SGECs respond to TLR signalling by producing IFN $\beta^{127,128}$. Interestingly, interferon production can be augmented by endogenous virus-like genomic repeat elements ('retroelements') ${ }^{129}$. The retroelement long interspersed nuclear element 1 (LINE-1) is overexpressed in the minor salivary gland tissue of patients with pSS, probably owing to hypomethylation in the promoter region of the gene encoding LINE-1 (REFS ${ }^{129,130}$ ). Importantly, LINE- 1 and IFN $\beta$ are expressed in the ductal epithelium ${ }^{129,130}$. Mechanistically, LINE-1 retroelements bind to cytosolic nucleic acid sensors, such as RIG-1-like receptors, and consequently trigger type I interferon production ${ }^{131}$. Vice versa, signalling downstream of extrinsic interferons can modulate the transcription of retroelements. For example, transcriptional modifications of Alu retroelements, induced by interferon signalling, enables this retroelement to bind to intracellular Ro60 (REFS ${ }^{129,132}$ ). Ro60 probably has an inhibitory role in type I interferon receptor signalling, as data have shown that deletion of Ro60 in an EBV-transformed B cell line increases interferon-induced pro-inflammatory cytokine production and the expression of retroelements ${ }^{132}$.

Similar to Ro60, Ro52 (later identified as TRIM21) has a multifaceted role in the innate immune response.
TRIM21 primarily functions simultaneously as a cytosolic Fc receptor and as an E3 ubiquitin-protein ligase $^{133,134}$. An important anti-viral role of TRIM21 is binding the Fc part of intracellular antibodies, directing endocytosed antibody-bound viral particles to the proteasome for degradation and activation of innate immune signalling ${ }^{134}$. Conversely, TRIM21 can also function as a negative regulator of TLR signalling by mediating ubiquitination (protein inactivation) of interferon-regulating factors (IRFs), such as IRF3, IRF5 and IRF7, thereby inhibiting interferon production ${ }^{135-137}$. An inhibitory role for TRIM21 is supported by studies of TRIM21-deficient C57BL/6 mice, which develop features of systemic autoimmunity upon local tissue injury ${ }^{138}$. Furthermore, the amount of anti-dsDNA antibody production and plasmablast formation is higher in TRIM21-deficient MRL/lpr mice than in wild type MRL/lpr mice, indicating enhanced B cell activation in the absence of TRIM21 (REF. ${ }^{139}$ ). Anti-Ro52/TRIM21 antibodies from patients with pSS can specifically recognize the RING domain of the TRIM21 protein. This RING domain is essential for the E3 ubiquitin ligase activity of TRIM2 1 and anti-Ro52 antibodies could interfere with this activity in vitro ${ }^{140}$. Although direct interference of anti-Ro52/TRIM21 antibodies (via their antigen-binding fragment (Fab) domain) with intracellular TRIM21 has not been proven in vivo, and is difficult to reconcile, aberrant function of TRIM21 upon uptake of autoantibody-containing immune complexes cannot be ruled out. For example, a study of mice with lupus-like disease provided evidence of possible leakage of IgG antibodies from phagolysosomes containing endocytosed immune complexes into the cytosol, which stimulated the TRIM21-mediated immune responses ${ }^{141}$. Furthermore, studies of patients with pSS have shown that TRIM21 can be expressed on the cell surface of antigen-presenting cells ${ }^{142}$, enabling transport of aggregated immunoglobulins and immune complexes into the cell. In conclusion, aberrant expression of retroelements and (indirect) interference of autoantibodies with the regulation of innate immune responses by TRIM21 (and possibly also Ro60) might result in a feed-forward loop of type I interferon activity in ductal epithelial cells, pDCs and B cells (FIG. 1 1 ). A main consequence for the glandular epithelium is that type I interferons enhance the production of pathogenic chemokines and cytokines (for example, CXCL10, IL-7 and BAFF) by ductal epithelial cells, resulting in the recruitment and activation of $\mathrm{T}$ cells and $\mathrm{B}$ cells and thereby amplifying the inflammatory response $^{58,143,144}$.

Type II interferons. In addition to type I interferons, type II interferons have also been implicated in pSSassociated salivary gland pathology. IFN $\gamma$ is mainly produced by natural killer cells and T cells as part of the innate and adaptive immune responses, respectively. In the salivary glands of patients with pSS, IFN $\gamma$ is abundantly produced by immune cells and the salivary gland tissue often has a mixed type I and type II interferon signature ${ }^{57,122}$. IFN $\gamma$ is not only produced by bona fide $\mathrm{T}_{\mathrm{H}} 1$ cells in the salivary gland but also by $\mathrm{T}$ follicular helper $\left(\mathrm{T}_{\mathrm{FH}}\right)$-like cells that express both 
programmed cell death protein 1 (PD1) and inducible $\mathrm{T}$ cell costimulator (ICOS) and by CCR9 ${ }^{+} \mathrm{T}$ helper cells ${ }^{145,146}$. IFN $\gamma$ exerts pro-inflammatory effects on SGECs (including both labial and parotid glandderived SGECs) by stimulating the production of cytokines and chemokines ${ }^{58,143}$. IFN $\gamma$ also induces the expression of MHC class II and co-stimulatory molecules on SGECs ${ }^{47,147,148}$. Collectively, these effects might result in immune cell activation ${ }^{46}$. IFN $\gamma$ can also induce FAS-mediated apoptosis and anoikis in SGECs ${ }^{47,48}$, although an opposite effect was observed in acinar cells and in an immortalized salivary gland ductal cell line, where IFN $\gamma$ induced apoptotic resistance ${ }^{25,46}$. IFN $\gamma$ has further been implicated in reducing the integrity of the glandular epithelium (that is, the tight junction barrier function), as has been observed in minor salivary gland tissue from patients with $\mathrm{pSS}^{106}$. Together, these results suggest that IFN $\gamma$ negatively affects SGECs in various ways, dependent on the glandular cell type, and might contribute to salivary gland dysfunction in patients with SS.

Type III interferons. Type III interferon has been added to the interferon family more recently ${ }^{149}$. Downstream effector genes of type III interferons are similar to those downstream of type I interferons and the functions of both interferon pathways largely overlap. However, an important difference is restricted expression of the type III interferon receptor by epithelial cells of mucosal surfaces and pDCs (reviewed elsewhere ${ }^{150}$ ). In the ductal epithelium of patients with pSS, IFN $\lambda 2$ is upregulated compared with individuals with non-Sjögren syndrome sicca symptoms ${ }^{151}$. Similar to type I and type II interferons, IFN $\lambda$ can promote the production of cytokines (for example, IL-7, BAFF and CXCL10) by the salivary gland epithelium ${ }^{58,151}$. Whether type III interferons notably contribute to salivary gland pathology, either independent or in synergy with other interferons, remains to be elucidated.

\section{Epithelial cell-lymphocyte crosstalk}

In healthy salivary glands, a small number of lymphocytes (in the form of $\mathrm{T}_{\mathrm{RM}}$ cells) are present for immune surveillance $^{60}$. By comparison, in pSS, CD8 ${ }^{+} \mathrm{T}$ cells are located in close association with acini or ducts with a disrupted basal lamina and $\mathrm{CD} 4^{+} \mathrm{T}$ cells are located in association with the ducts ${ }^{37}$. B cells can also infiltrate the ductal epithelium, a phenomenon that is specific to $\mathrm{pSS}^{10}$. Such histological findings suggest that crosstalk between the salivary gland epithelium and lymphocytes has a critical role in salivary gland pathology. In this section, we focus on crosstalk between epithelial cells of the salivary glands and lymphocytes (specifically, $\mathrm{CD}^{+} \mathrm{T}$ cells and intraepithelial B cells) in pSS.

\section{Crosstalk with $\mathrm{CD4}^{+} \mathrm{T}$ cells}

The presence of MHC class II in combination with CD80 and CD86 molecules on the surface of SGECs upon immune activation (for example, following stimulation with IFN $\gamma$ ) infers the ability of the epithelial cells to process antigens for presentation to $\mathrm{CD} 4^{+}$ $\mathrm{T}_{\text {cells }}{ }^{52,152}$. In the presence of $\mathrm{T}$ cell receptor stimulation, constitutive expression of CD86 by SGEC lines could promote $\mathrm{CD} 4^{+} \mathrm{T}$ cell proliferation by engaging with CD28 (REF. ${ }^{153}$ ). SGECs from patients with pSS are also capable of expressing other co-stimulatory molecules such as CD40 and ICOS ligand (ICOSL) ${ }^{49,152,154}$. In SGECs from patients with pSS, CD40 is spontaneously expressed (at higher levels than in SGECs from patients with sicca symptoms but not diagnosed with pSS) and this expression can be enhanced in the presence of IFN $\gamma$ or IL- $1 \beta^{148}$. Ligation of CD40 on SGECs activates the non-canonical NF- $\kappa \mathrm{B}$ pathway, resulting in pro-inflammatory cytokine production and either FAS-dependent apoptosis or apoptotic resistance ${ }^{49,155}$, probably depending on the epithelial cell type and microenvironmental cues. However, although SGECs seem to express all molecules required for antigen presentation, no formal proof is yet available showing that human SGECs actively present antigen to $\mathrm{T}$ cells via cognate interaction in vivo.

In addition to the provision of co-stimulatory signals to T cells, SGECs can produce several cytokines and chemokines, as shown for both labial and parotid gland-derived SGECs. These can include chemokines that attract T cells (for example, CCL19 and CXCL10), as well as cytokines that promote local $\mathrm{T}$ cell proliferation and/or differentiation ${ }^{56,58,143,154}$. For example, SGECs can produce IL-6, a pleiotropic cytokine that can promote the differentiation of $\mathrm{T}_{\mathrm{FH}}$ cells (as well as B cells) ${ }^{156}$. IL-6 production by SGECs, together with ICOSL expression on these SGECs, can support the differentiation of $\mathrm{T}_{\mathrm{FH}}$ cells in vitro ${ }^{154}$. This finding is notable as the expansion of both glandular and circulating $\mathrm{T}_{\mathrm{FH}}$ cells in pSS is associated with more severe disease, that is, increased ESSDAI scores, IgG antibody production and ectopic lymphoid structure formation ${ }^{146,157,158}$.

Another potentially relevant cytokine for salivary gland epithelium-T cell crosstalk is IL-7. This cytokine is produced by non-haematopoietic cells and has an important role in $\mathrm{T}$ cell homeostasis ${ }^{159}$. Although a histological study in minor salivary glands found that IL-7 was mostly expressed by cells with a fibroblast morphology in the interstitium, and not by acinar or ductal cells ${ }^{160}$, more recent findings suggest that IL-7 is also expressed by SGECs ${ }^{58,121}$. Cultured SGECs from patients with pSS produce IL-7 after stimulation with poly(I:C), IFNa or IFN $\gamma^{58}$. Data from the B6.NOD-Aec mouse model of pSS suggest that IL-7 also has an indirect role in salivary gland pathology, by enhancing $\mathrm{T}_{\mathrm{H}} 1$ responses and IFN $\gamma$-dependent CXCL10 expression in the salivary gland $^{161}$. Thus, activation of $\mathrm{T}_{\mathrm{H}} 1$ cells by IL-7 can propagate IFN $\gamma$ production, creating a pro-inflammatory loop. Although the epithelial source of IL-7 production (for example, ductal or acinar cells) has not been studied, various data suggest that the IL-7-IL-7Ra axis contributes to $\mathrm{T}$ cell-driven autoimmune pathology in pSS. For example, the amount of IL-7R-positive T cells in the salivary glands of patients with pSS correlates with IL-7 expression and the severity of sialadenitis ${ }^{162}$. In addition, CCR9 ${ }^{+} \mathrm{T}$ helper cells typically express high levels of the IL-7 receptor and stimulation of these cells with IL-7 induces IFN $\gamma$, IL-17 and IL-21 production, thereby also supporting B cell activation ${ }^{145}$. 


\section{Crosstalk with B cells}

Available evidence indicates that the salivary gland epithelium is able to promote B cell hyperactivity in pSS and forms a niche for autoantibody-producing plasma cells. Chronic B cell hyperactivity in the salivary glands is demonstrated, amongst others findings, by the frequent occurrence of ectopic lymphoid structures in the glandular tissue, which might even contain germinal centres ${ }^{7}$, and by the high risk of patients with pSS developing $B$ cell non-Hodgkin lymphomas in these glands ${ }^{163}$. Several mechanisms underlying B cell hyperactivity in pSS have been described and reviewed elsewhere ${ }^{8,9}$. In this section, we focus on the crosstalk between epithelial cells and B cells and highlight novel insights into the development of LELs and MALT lymphoma in PSS.

$B$ cell activation by the salivary gland epithelium. Epithelial cells can contribute to B cell activity through the production of cytokines, including IL- 6 and BAFF $^{121,154,164}$. Both IL- 6 and BAFF are involved in $\mathrm{B}$ cell activation and homeostasis, and BAFF is critically important for $\mathrm{B}$ cell survival ${ }^{15,165,166}$. Previous reports have shown that type I interferon is an important promoter of BAFF production by SGECs ${ }^{6,144,167}$. The expression of interferon-inducible genes was indeed increased in EpCAM-positive epithelial cells in biopsy samples from patients with pSS compared with biopsy samples from individuals with non-Sjögren syndrome sicca symptoms ${ }^{121}$. In one study that employed co-cultures of B cells and SGECs, poly(I:C) stimulated the production of soluble factors by SGECs from patients with pSS, which enhanced the survival of the B cells ${ }^{121}$. Surprisingly, blockade of a proliferation-inducing ligand (APRIL) or BAFF alone had no effect on $B$ cell survival ${ }^{121}$, suggesting that other factors might be responsible for enhanced $B$ cell survival under this experimental condition.

The epithelium not only affects B cells, but B cells can also, vice versa, have effects on epithelial cells. For example, B cells can induce epigenetic modifications in $\mathrm{SGECs}^{168}$. B cell-induced transcriptional changes in epithelial cells might contribute to the formation of LELs, as discussed in the next section.

Lymphoepithelial lesion development. The intimate relationship between the salivary gland epithelium and $\mathrm{B}$ cells in $\mathrm{PSS}$ is most clearly demonstrated by the presence of LELs (FIG. 2). These LELs develop exclusively in the striated ducts and are a characteristic histological feature of $\mathrm{pSS}^{11}$. LELs are formed in close association with the periductal infiltrate ${ }^{10,11}$. Although these lesions are found in both the minor and major salivary glands, they are more pronounced in the major (parotid) glands ${ }^{10}$. LELs consist of hyperplastic duct cells in the epithelial cell lining and infiltrating lymphocytes within the contour of the basement membrane ${ }^{11}$. This hyperplasia might result in complete occlusion of the ducts, potentially contributing to hyposalivation. Evidence suggests that LELs nearly always harbour B cells in between the hyperplastic basal cells and that a small proportion of the striated ducts without hyperplasia already contain some $\mathrm{B}$ cells ${ }^{10}$. In addition, some intraepithelial T cells are also found in LELs; however, unlike B cells, which are completely absent from the salivary gland ducts of patients with non-Sjögren syndrome sicca symptoms, the presence of intraepithelial $\mathrm{T}$ cells is not specific to $\mathrm{pSS}^{10}$. Together these findings suggest that LEL formation starts with the infiltration of B cells into the ductal epithelium. The severity of the LEL (stage of duct occlusion) increases with the absolute and relative number of intraepithelial B cells ${ }^{10}$. How B cells are attracted into the epithelium is not fully understood, but the expression of CXCR3 probably has an important role, as intraepithelial B cells express CXCR3 and the salivary gland epithelium produces CXCL10 and other CXCR3 ligands upon activation ${ }^{143}$. These intraepithelial B cells, which are probably already activated before they migrate to the epithelium, can expand locally, as demonstrated by the high proportion of Ki67-staining cells and the expansion of clonal B cells within the striated ducts ${ }^{169,170}$. The latter finding suggests that additional activation and proliferation signals might be derived from epithelial cells, and possibly also from other intraepithelial immune cells, such as $\mathrm{T}$ cells and dendritic cells.

Interestingly, the majority, if not all, of the intraepithelial B cells in the minor (labial) and major (parotid) glands express the inhibitory Fc-receptor like 4 (FcRL4) protein (FIC. 3), which is abundantly expressed by MALT lymphoma B cells of patients with $\mathrm{pSS}^{169}$, and is also expressed on activated B cells ${ }^{171}$. Gene expression profiling of FcRL $4^{+} \mathrm{B}$ cells from parotid gland tissue of patients with pSS has further revealed that these cells express transcripts of chronic activation markers, such as T-bet
HEE

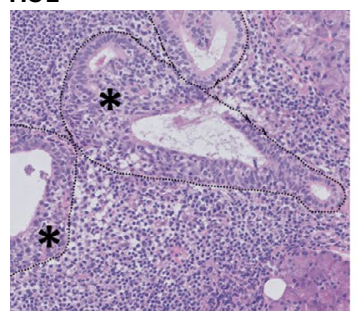

hmwCK

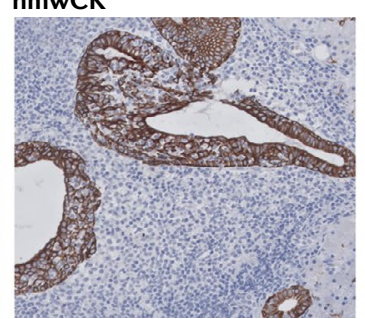

CD20

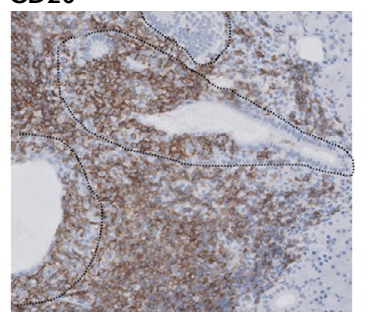

CD3

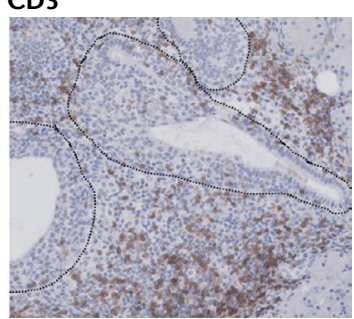

Fig. 2 | Lymphoepithelial lesions in the salivary glands of a patient with primary Sjögren syndrome. Consecutive sections of parotid gland tissue from a patient with primary Sjögren syndrome are shown. Lymphoepithelial lesions are indicated by an asterisk on the haematoxylin and eosin (HEE)-stained section. Consecutive sections were stained with antibodies to reveal either epithelial cells (using antibodies against high molecular weight cytokeratin (hmwCK)), B cells (using antibodies against CD20) or T cells (using antibodies against CD3). B cells dominate the lymphoepithelial lesions, whereas T cells are rarely detected within these structures. Image courtesy of M.S. van Ginkel and B. van der Vegt. 


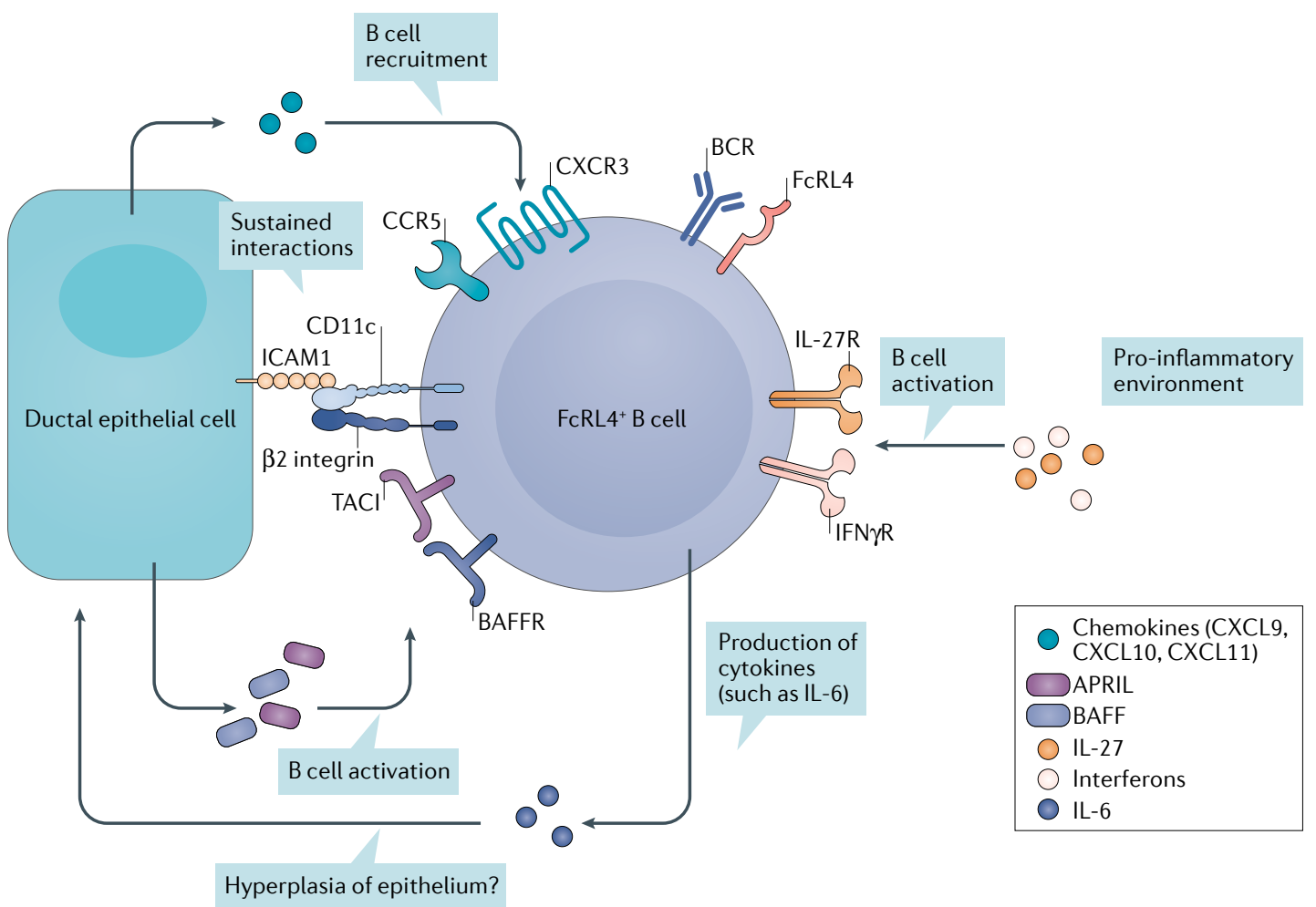

Fig. 3 | Interactions between FcRL4+ B cells and the ductal epithelium in primary Sjögren syndrome. a | Activated epithelial cells secrete $\mathrm{CXCL10}$ and attract Fc-receptor like 4-positive (FcRL4+) B cells. These cells are further activated by $B$ cell-activating factor (BAFF) and a proliferation-inducing ligand (APRIL), secreted by epithelial cells, and other stimuli from the pro-inflammatory environment. Upon activation, FcRL4 ${ }^{+} B$ cells express CD11c, which can form an integrin together with the $\beta 2$ integrin. This integrin can bind to intercellular adhesion molecule 1 (ICAM1) on epithelial cells and sustain their interaction. The production of IL- 6 and possibly also other pro-inflammatory cytokines by FcRL $4^{+} B$ cells might result in hyperplasia of the epithelium.

and CD11 $\mathrm{c}^{172}$. T-bet expression might be the result of a type II interferon response, as the expression of IFNGR1 and IL27RA is upregulated in FcRL4 ${ }^{+} \mathrm{B}$ cells ${ }^{172}$. Indeed, signalling downstream of the IFN $\gamma$ receptor and IL-27 receptor in $\mathrm{B}$ cells induces the expression of T-bet, via STAT1, and such signalling pathways have been implicated in the development of autoimmunity in mice ${ }^{173-176}$. $\mathrm{FcRL}^{+} \mathrm{B}$ cells also have increased expression of TACI (encoding the receptor for BAFF and APRIL), CXCR3, CCR5, NF- $\mathrm{BB}$-related genes (NFKB1 and MAP3K14) and $I L 6$, and reduced expression of negative regulators of NF- $\kappa \mathrm{B}$ (NFKBIA and NFKBID, encoding I $\kappa \mathrm{B} \alpha$ and IкBNS, respectively), CD40 and CXCR5 compared with FcRL4- glandular B cells. These phenotypical characteristics suggest that FcRL4 ${ }^{+} \mathrm{B}$ cells are activated cells that persist in inflamed tissue and are sustained by pro-inflammatory cytokines (in particular IFN $\gamma$, IL-27, BAFF and APRIL) and CD40-independent stimulation.

Glandular FcRL4 ${ }^{+} \mathrm{B}$ cells resemble double-negative $\left(\mathrm{IgD}^{-} \mathrm{CD} 27^{-}\right) \mathrm{B}$ cells (called DN2 B cells), a cell type also characterized by T-bet and CD11c expression that is associated with the pathogenesis of SLE ${ }^{177,178}$. In patients with SLE, CD11 $\mathrm{c}^{+} \mathrm{T}^{- \text {bet }^{+}} \mathrm{B}$ cells are poised to differentiate into plasmablasts outside of the follicles ${ }^{177,178}$. However, glandular FcRL4 ${ }^{+}$B cells in patients with pSS lack the expression of plasma cell markers, such as $\mathrm{B}$ lymphocyte-induced maturation protein 1 (BLIMP1; also known as PRDM1) ${ }^{169}$. Available evidence indicates that binding of soluble IgA to FcRL4 results in a switch from $\mathrm{B}$ cell receptor (BCR)-mediated activation to TLR-mediated activation ${ }^{179}$. This functional switch of the $B$ cells probably results in enhanced NF- $\kappa B$ pathway activation and cytokine production. Secreted cytokines of intraepithelial B cells, such as IL-6, might affect epithelial homeostasis and lead to the proliferation of epithelial cells and ultimately to LEL formation. Direct proof that B cells are involved in LEL formation comes from trials of rituximab (a B cell-depleting agent) in patients with pSS. Treatment of patients with pSS with rituximab not only led to a strong reduction of B cells within the salivary gland, including B cells located within the epithelium, but concomitantly also led to a reduction in the severity of the LELs and the partial restoration of the epithelium after 12 weeks of treatment ${ }^{180}$. Notably, salivary gland B cell depletion was more variable at week 24 in this study ${ }^{181}$, suggesting that in some patients, B cells have started to repopulate the glands at this time point. Although rituximab treatment had clear effects on salivary gland histopathology, in particular at early time points, these effects unfortunately did not translate into rituximab having a proven clinical efficacy in $\mathrm{pSS}^{182-184}$.

The effects of B cell depletion therapy on the epithelium using rituximab, together with the cytokine profiles of intraepithelial B cells and SGECs, suggest that some 
crosstalk occurs between B cells and striated duct epithelial cells, leading to sustained activation and proliferation of both cell types. Upregulation of CXCR3 and CD11c, and possibly also other integrins, on the $\mathrm{B}$ cell surface might have a role in keeping the cells within the epithelial layer. However, in addition to being present in ductal areas, $\mathrm{B}$ cell clones are also present, to some extent, in the periductal areas, suggesting that some cellular exchange occurs between these areas ${ }^{170}$.

The lack of mRNA and protein expression of plasma cell markers by glandular FcRL4 ${ }^{+} \mathrm{B}$ cells suggest that these cells rarely differentiate into plasmablasts and instead the cells are maintained in a state of chronic activation and continue to proliferate at a high rate $\mathrm{reg}^{169,172}$. These cells might undergo extrafollicular somatic hypermutation; indeed, activation induced deaminase (AID), the enzyme responsible for initiating diversity in immunoglobulin genes during somatic hypermutation (and class switching), is expressed by FcRL4 ${ }^{+} \mathrm{B}$ cells in the tonsils (and possibly also in salivary glands) ${ }^{185}$. Notably, AID expression, which can be induced by T-bet ${ }^{186}$, might not only result in hypermutation of immunoglobulin variable region genes, but also in off-target mutations (that is, non-immunoglobulin genes) ${ }^{187}$. Thus, a pathogenic combination of increased NF- $\kappa \mathrm{B}$ activation, pro-survival factors, proliferation and possibly also AID expression in FcRL4 ${ }^{+}$intraepithelial B cells could make these cells prone to neoplastic changes and promote progression towards MALT lymphoma, as discussed in the next section.

MALT lymphoma and rheumatoid factor-expressing $B$ cells. Non-Hodgkin lymphomas arise in $5-10 \%$ of patients with pSS, and the majority of these lymphomas are MALT lymphomas that develop preferentially within the parotid glands ${ }^{163}$. A hallmark of salivary gland MALT lymphomas is their association with LELs, highlighting the dependency of these lymphomas on epithelial cells. MALT lymphomas are considered to arise as a consequence of chronic B cell stimulation and, in pSS, these neoplastic cells often express stereotypic rheumatoid factors that have a high affinity for the Fc region of IgG antibodies $^{188-190}$. In patients with pSS, non-neoplastic rheumatoid factor-expressing B cells are enriched within the circulating CD21-/low $\mathrm{B}$ cell population ${ }^{191}$, a phenotype that is associated with impaired BCR stimulation (similar to FcRL4 $4^{+}$B cells) and frequent polyreactivity or self-reactivity ${ }^{192,193}$. The phenotype of CD21 $1^{- \text {llow }} \mathrm{B}$ cells partially overlaps with DN2 B cells ${ }^{194}$. Notably, IL-21 and TLR7 ligands together promote the expansion and differentiation of DN2 B cells ${ }^{178}$ and are both readily available in the inflamed salivary gland in patients with $\mathrm{pSS}^{146}$. While the frequency of rheumatoid factor-expressing $B$ cells in the inflamed salivary glands of patients with pSS without MALT lymphoma seems to be low ${ }^{195,196}$, these cells might expand after dual engagement of the BCR and TLRs with immune complexes that contain RNA-associated autoantigens ${ }^{197}$. Although the role of the BCR in lymphomatous escape remains enigmatic, rheumatoid factor expressed on the surface of B cells might simply trap immune complexes of autoantibodies and RNA-associated autoantigens, which stimulate
TLRs, with or without further BCR-mediated activation of the cells. In the inflamed salivary gland, these immune complexes might provide chronic B cell stimulation and a strong selection advantage of incidental stereotypic rheumatoid factor-expressing B cells. Simultaneous engagement of FcRL4 on these B cells might inhibit differentiation towards plasma cells and in turn enable ongoing proliferation.

Rheumatoid factor-expressing B cells frequently express IGHV1-69, a immunoglobulin heavy-chain variable region variant that can be detected by the monoclonal antibody G6 (REF. $\left.{ }^{198}\right)$. Compared with healthy individuals, patients with pSS and cryoglobulinaemic vasculitis have an increased frequency of G6-positive memory B cells on the periphery, which exclusively express kappa light chains ${ }^{191}$. Interestingly, all MALT lymphomas that have rheumatoid factor activity are IgM clones with kappa light chains ${ }^{188,190}$, suggesting that $\mathrm{G6}^{+}$ B cells might form a pool of potential precursor cells to MALT lymphomas. Furthermore, researchers have shown that $\mathrm{G}^{+} \mathrm{B}$ cells incidentally contain somatic mutations in genes involved in B cell proliferation, such as TNFAIP3 (REF. ${ }^{191}$ ). A specific germline polymorphism of TNFAIP3 is associated with MALT lymphoma development in $\mathrm{pSS}^{199}$, underlining the importance of intact $\mathrm{NF}-\kappa \mathrm{B}$ regulation in preventing $\mathrm{B}$ cell dysregulation. Variations in B cell-regulating genes, such as TNFAIP3, might result in the escape of autoreactive cells from tolerance checkpoints ${ }^{191}$. Although the presence of $\mathrm{G6}^{+}$ $\mathrm{B}$ cells that contain lymphoma-associated mutations in the peripheral blood of patients with pSS has not been linked directly to MALT lymphoma development, these cells might migrate to the salivary glands, where they could be further activated.

Taken together, an attractive hypothesis is that the highly proliferative, intraepithelial FcRL4 $4^{+} \mathrm{B}$ cells are the glandular counterparts of DN2 B cells, incidentally displaying rheumatoid factor reactivity and forming a pool of lymphoma precursor cells in the salivary glands of patients with pSS. The notion that FcRL4 $4^{+} \mathrm{B}$ cells are more frequently observed in parotid glands compared with labial glands might explain the preferential development of MALT lymphoma in parotid glands ${ }^{169}$. Although the critical steps towards neoplastic dysregulation of glandular B cells remain unknown, somatic mutations within and outside of the immunoglobulin variable region genes are probably involved. We postulate that therapeutic targeting of intraepithelial B cells might prevent the development of MALT lymphoma in patients with pSS.

\section{Future directions}

Over the past decade, the attenuation of sicca symptoms and, more recently, the attenuation of systemic disease activity have evolved as main treatment targets in pSS. As the epithelium is the functional backbone of the salivary gland, its restoration must be a central determinant of future therapies aimed at targeting hyposalivation in pSS. We hypothesize that therapies that target, for example, only the immune system might reduce glandular inflammation but not necessarily rescue salivary gland function, as demonstrated in existing clinical trials ${ }^{200}$. 
Although the targeting of the immune system is a valid approach in pSS, considering the typical (auto)immune manifestations and systemic nature of the disease, more attention should be paid to the correction of epithelial defects. Multifaceted approaches that consist of both an anti-inflammatory and a pro-epithelial component - for example, immunotherapy combined with cell therapy might provide the crucial regenerative stimuli required to correct these defects.

With regard to cell therapy, fresh, patient-matched induced pluripotent stem cells might be used to derive untainted salivary gland acinar and/or ductal cells, which could subsequently be transplanted back into the patient. The relatively new drug class senolytics (a class of drugs that selectively induce death of senescent cells) might also prove therapeutically useful in the depletion of senescent epithelial progenitor cells, limiting further damage that would otherwise be inflicted by these cells ${ }^{201,202}$. The timing of therapy application is probably an important consideration, given the general early loss of salivary gland function in pSS. More advanced stages of glandular disease are characterized by the dominance of B cells and the presence of LELs, and in these patients, glandular B cells are an important treatment target. As previously highlighted, B cell depletion therapy with rituximab reduced the severity of LELs ${ }^{180}$, but whether other B cell-directed therapies also target these pathogenic structures remains to be examined. In-depth histological evaluation of glandular tissue in clinical trials is, in this context, a valuable outcome measure of clinical trials.

Dissection and identification of specific defects at the individual patient level might be the key to successful treatment, given the variety of inflammatory pathways involved in the pathogenesis of pSS. Therefore, treatment decisions guided by the clinical picture of the salivary gland hold promise. To define the clinical picture of the salivary gland in individual patients, imaging and in-depth histopathological examinations of salivary gland biopsy samples are needed, going beyond measuring the focus score. In addition, tissue transcriptomics, in particular at the single-cell level, might be useful to identify dysregulated pathways. Lastly, the scientific community is advancing with the establishment of in vitro models of salivary gland disease (for example, co-cultures of organoids or explants with immune cells) ${ }^{58,68,121}$ to screen for new drug targets and to examine the effect of immunomodulatory treatments on salivary gland function.

\section{Conclusions}

Overall, a multitude of pathways, systems and processes are probably dysregulated in the salivary gland in pSS, including defects that affect the epithelium, innate immune signalling and adaptive immune activation. In an ideal world, each defect would be corrected, and the salivary gland restored to its naive state. Although the initial triggers that activate the salivary gland epithelium remain undetermined, the nature of the local immune response, including dominant type I interferon activity, hints at the involvement of a viral infection. Subsequent dysregulation of the immune response, possibly owing to interference of type I interferon signalling by autoantibodies and chronic autoantigen exposure by apoptotic epithelial cells, results in a pro-inflammatory feedback loop. Various immune cells (such as lymphocytes, dendritic cells and macrophages) might interact with the epithelium and contribute to the inflammatory response. In particular, crosstalk between the ductal epithelium and B cells, and consequently the formation of LELs, negatively affects salivary gland morphology and might result in MALT lymphoma development. Finally, as a scientific community, we need to think more abstractly, and consider combining immunotherapy with cell therapies to provide an unfettered source of SGECs, although preventing continual resurgence of the same epithelial problems will remain a challenge.

\section{Published online 28 April 2021}

1. Sjögren, H. Zur Kenntnis der Keratoconjunctivitis sicca (Keratitis filiformis bei Hypofunktion der Tränendrüsen). Acta Ophthalmol. 11 (Suppl. 2), 1-51 (1933).

2. Brito-Zerón, P. et al. Sjögren syndrome. Nat. Rev. Dis. Primers 2, 16047 (2016).

3. Shiboski, C. H. et al. 2016 American College of Rheumatology/European League Against Rheumatism classification criteria for primary Sjögren's syndrome: a consensus and data-driven methodology involving three international patient cohorts. Arthritis Rheumatol. 69, 35-45 (2017).

4. Greenspan, J. S., Daniels, T. E., Talal, N. \& Sylvester, R. A. The histopathology of Sjögren's syndrome in labial salivary gland biopsies. Oral Surg. Oral Med. Oral Pathol. 37, 217-229 (1974).

5. Christodoulou, M. I., Kapsogeorgou, E. K. \& Moutsopoulos, H. M. Characteristics of the minor salivary gland infiltrates in Sjogren's syndrome. J. Autoimmun. 34, 400-407 (2010).

6. Gottenberg, J. E. et al. Activation of IFN pathways and plasmacytoid dendritic cell recruitment in target organs of primary Sjogren's syndrome. Proc. Natl Acad Sci USA 103, 2770-2775 (2006).

7. Bombardieri, M., Lewis, M. \& Pitzalis, C. Ectopic lymphoid neogenesis in rheumatic autoimmune diseases. Nat. Rev. Rheumatol. 13, 141-154 (2017).

8. Nocturne, G. \& Mariette, X. B cells in the pathogenesis of primary Sjögren syndrome. Nat. Rev. Rheumatol. 14, 133-145 (2018).

9. Kroese, F. G. et al. B-cell hyperactivity in primary Sjogren's syndrome. Expert Rev. Clin. Immunol. 10, 483-499 (2014)
10. van Ginkel, M. S. et al. Presence of intraepithelial B-lymphocytes is associated with the formation of lymphoepithelial lesions in salivary glands of primary Sjögren's syndrome patients. Clin. Exp. Rheumatol. 37, s42-s48 (2019).

11. Ihrler, S., Zietz, C., Sendelhofert, A., Riederer, A. \& Lohrs, U. Lymphoepithelial duct lesions in Sjogren-type sialadenitis. Virchows Arch. 434, 315-323 (1999)

12. Tengnér, P., Halse, A., Haga, H., Jonsson, R. \& Wahren-Herlenius, M. Detection of anti-Ro/SSA and anti-La/SSB autoantibody-producing cells in salivary glands from patients with Sjögren's syndrome. Arthritis Rheum. 41, 2238-2248 (1998).

13. Kyriakidis, N. C., Kapsogeorgou, E. K. \& Tzioufas, A. G A comprehensive review of autoantibodies in primary Sjögren's syndrome: Clinical phenotypes and regulatory mechanisms. J. Autoimmun. 51, 67-74 (2014).

14. Theander, E. et al. Prediction of Sjögren's Syndrome years before diagnosis and identification of patients with early onset and severe disease course by autoantibody profiling. Arthritis Rheumatol 67 2427-2436 (2015).

15. Dawes, C. \& Wood, C. M. The contribution of oral minor mucous gland secretions to the volume of whole saliva in man. Arch. Oral. Biol. 18, 337-342 (1973).

16. Jonsson, R., Kroneld, U., Backman, K., Magnusson, M $\&$ Tarkowskit, A. Progression of sialadenitis in Sjögren's sydrome. Br. J. Rheumatol. 32, 578-581 (1993).
17. Bookman, A. A. M. et al. Whole stimulated salivary flow: correlation with the pathology of inflammation and damage in minor salivary gland biopsy specimens from patients with primary Sjögren's syndrome but not patients with sicca. Arthritis Rheum. 63, 2014-2020 (2011).

18. Kalk, W. W. et al. Sialometry and sialochemistry: diagnostic tools for Sjogren's syndrome. Ann. Rheum. Dis. 60, 1110-1116 (2001).

19. Pedersen, A. M. L., Bardow, A. \& Nauntofte, B. Salivary changes and dental caries as potential oral markers of autoimmune salivary gland dysfunction in primary Sjögren's syndrome. BMC Clin. Pathol. 5 $1-13$ (2005).

20. Mandel, I. D. \& Baurmash, H. Sialochemistry in Sjögren's syndrome. Oral Surgery Oral Med. Oral Pathol. 41, 182-187 (1976).

21. Herrera-Esparza, R. et al. Apoptosis and cell proliferation: the paradox of salivary glands in Sjögren's disease. Acta Reumatol. Port. 33, 299-303 (2020).

22. Ohlsson, M., Skarstein, K., Bolstad, A. I. Johannessen, A. C. \& Jonsson, R. Fas-induced apoptosis is a rare event in Sjögren's syndrome. Lab. Invest. 81, 95-105 (2001).

23. Polihronis, M. et al. Modes of epithelial cell death and repair in Sjogren's syndrome (SS). Clin. Exp. Immunol. 114, 485-490 (1998).

24. Calafat, M. et al. Vasoactive intestinal peptide inhibits TNF- $\alpha$-induced apoptotic events in acinar cells from nonobese diabetic mice submandibular glands. Arthritis Res. Ther. 11, R53 (2009). 
25. Barrera, M. J. et al. Pro-inflammatory cytokines enhance ERAD and ATF6 a pathway activity in salivary glands of Sjögren's syndrome patients. J. Autoimmun. 75, 68-81 (2016).

26. Bouma, H. et al. Aging and immunopathology in primary Sjögren's syndrome. Curr. Aging Sci. 8 202-213 (2015)

27. Ambudkar, I. Calcium signaling defects underlying salivary gland dysfunction. Biochim. Biophys. Acta Mol. Cell Res. 1865, 1771-1777 (2018).

28. Waterman, S. A., Gordon, T. P. \& Rischmueller, M. Inhibitory effects of muscarinic receptor autoantibodies on parasympathetic neurotransmission in Sjögren's syndrome. Arthritis Rheum. 43, 1647-1654 (2000)

29. Teos, L. Y. et al. IP3R deficit underlies loss of salivary fluid secretion in Sjögren's Syndrome. Sci. Rep. 5 13953 (2015).

30. Cortés, J. et al. Synaptotagmin-1 overexpression under inflammatory conditions affects secretion in salivary glands from Sjögren's syndrome patients. J. Autoimmun. 97, 88-99 (2019).

31. Cortes-Troncoso, J. et al. T cell exosome-derived miR-142-3p impairs glandular cell function in Sjögren's syndrome. JCI Insight 5, e 133497 (2020).

32. Ichiyama, T. et al. Expression of aquaporin 3 and 5 as a potential marker for distinguishing dry mouth from Sjögren's syndrome. J. Oral Sci. 60, 21 2-220 (2018).

33. Enger, T. B., Aure, M. H., Jensen, J. L. \& Galtung, H. K. Calcium signaling and cell volume regulation are altered in Sjögren's syndrome. Acta Odontol. Scand. 72, 549-556 (2013)

34. Wu, A. M., Csako, G. \& Herp, A. Structure biosynthesis, and function of salivary mucins. Mol. Cell. Biochem. 137, 39-55 (1994).

35. Sung, H. H. et al. MUC1/SEC and MUC1/Y overexpression is associated with inflammation in Sjögren's syndrome. Oral Dis. 21, 730-738 (2015).

36. Barrera, M. J. et al. Salivary mucins induce a Toll-like receptor 4-mediated pro-inflammatory response in human submandibular salivary cells: are mucins involved in Sjögren's syndrome? Rheumatology $\mathbf{5 4}$ 1518-1527 (2015).

37. Molina, C. et al. Basal lamina disorganisation of the acini and ducts of labial salivary glands from patients with Sjögren's syndrome: association with mononuclear cell infiltration. Ann. Rheum. Dis. 65, 178-183 (2006)

38. Castro, I. et al. Aberrant MUC1 accumulation in salivary glands of Sjögren's syndrome patients is reversed by TUDCA in vitro. Rheumatology 59 , 742-753 (2020)

39. Bunya, V. Y. et al. Prevalence of novel candidate Sjögren syndrome autoantibodies in the penn Sjögren's international collaborative clinical alliance cohort. Cornea 38, 1500-1505 (2019).

40. Shen, L. et al. Evaluation of salivary gland protein 1 antibodies in patients with primary and secondary Sjogren's syndrome. Clin. Immunol. 155, 42-46 (2014).

41. Shen, L. et al. Novel autoantibodies in Sjogren's syndrome. Clin. Immunol. 145, 251-255 (2012).

42. Vila, T., Rizk, A. M., Sultan, A. S. \& Jabra-Rizk, M. A The power of saliva: antimicrobial and beyond. PLoS Pathog. 15, e 1008058 (2019)

43. Pijpe, J. et al. Progression of salivary gland dysfunction in patients with Sjogren's syndrome. Ann. Rheum. Dis. 66, 107-112 (2007).

44. Kalk, W. W. I. et al. Sialometry and sialochemistry: a non-invasive approach for diagnosing Sjögren's syndrome. Ann. Rheum. Dis. 61, 137-144 (2002).

45. Kurth, B. E., Hazen-Martin, D. J., Sens, M. A. DeChamplain, R. W. \& Sens, D. A. Cell culture and characterization of human minor salivary gland duct cells. J. Oral Pathol. Med. 18, 214-219 (1989).

46. Matsumura, R. et al. Interferon gamma and tumo necrosis factor alpha induce Fas expression and anti-Fas mediated apoptosis in a salivary ductal cell line Clin Exp. Rheumatol. 18, 311-318 (2020).

47. Abu-Helu, R. F., Dimitriou, I. D., Kapsogeorgou, E. K., Moutsopoulos, H. M. \& Manoussakis, M. N. Induction of salivary gland epithelial cell injury in sjogren's syndrome: in vitro assessment of T cell-derived cytokines and fas protein expression. J. Autoimmun 17, 141-153 (2001)

48. Manoussakis, M. N., Spachidou, M. P. \& Maratheftis, C. I. Salivary epithelial cells from Sjogren's syndrome patients are highly sensitive to anoikis induced by TLR-3 ligation. J. Autoimmun 35, 212-218 (2010)

49. Ohlsson, M., Szodoray, P., Loro, L. L., Johannessen, A. C. \& Jonsson, R. CD40, CD154, Bax and Bcl-2 expression in Sjogren's syndrome salivary glands: a putative anti-apoptotic role during its effector phases. Scand. J. Immunol. 56, 561-571 (2002).

50. Ping, L., Ogawa, N. \& Sugai, S. Novel role of CD40 in Fas-dependent apoptosis of cultured salivary epithelia cells from patients with Sjögren's syndrome. Arthritis Rheum. 52, 573-581 (2005).

51. Sisto, M. et al. Autoantibodies from Sjögren's syndrome trigger apoptosis in salivary gland cell line. Ann. NY Acad. Sci. 1108, 418-425 (2007).

52. Manoussakis, M. N. \& Kapsogeorgou, E. K. The role of intrinsic epithelial activation in the pathogenesis of Sjögren's syndrome. J. Autoimmun. 35, 219-224 (2010).

53. Kawakami, A. et al. Toll-like receptor in salivary glands from patients with Sjögren's syndrome: functional analysis by human salivary gland cell line. J. Rheumatol. 34, 1019-1026 (2007).

54. Spachidou, M. P. et al. Expression of functional Toll-like receptors by salivary gland epithelial cells: increased mRNA expression in cells derived from patients with primary Sjögren's syndrome. Clin. Exp. Immunol 147, 497-503 (2007).

55. Sfriso, P. et al. Epithelial CXCR3-B regulates chemokines bioavailability in normal, but not in Sjogren's syndrome, salivary glands. J. Immunol. 176 , 2581-2589 (2006).

56. Xanthou, G. et al. 'Lymphoid' chemokine messenger RNA expression by epithelial cells in the chronic inflammatory lesion of the salivary glands of Sjögren's syndrome patients: possible participation in lymphoid structure formation. Arthritis Rheum. 44, 408-418 (2001).

57. Fox, R. I., Kang, H. I., Ando, D., Abrams, J. \& Pisa, E. Cytokine mRNA expression in salivary gland biopsies of Sjögren's syndrome. J. Immunol. 152, 5532-5539 (1994).

58. Rivière, E. et al. Interleukin-7/interferon axis drives T-cell and salivary gland epithelial cell interactions in Sjögren's syndrome. Arthritis Rheumatol. 73 631-640 (2021).

59. Cortez, V. S. et al. Transforming growth factor $-\beta$ signaling guides the differentiation of innate lymphoid cells in salivary glands. Immunity 44, 1127-1139 (2016).

60. Stolp, B. et al. Salivary gland macrophages and tissue-resident $\mathrm{CD} 8^{+} \mathrm{T}$ cells cooperate for homeostatic organ surveillance. Sci. Immunol. 5, eaaz4371 (2020).

61. Pringle, S. et al. Human salivary gland stem cells functionally restore radiation damaged salivary glands. Stem Cells 34, 640-652 (2016)

62. Hauser, B. R., Aure, M. H., Kelly, M. C., Hoffman, M. P. $\&$ Chibly, A. M. Generation of a single-cell RNAseq atlas of murine salivary gland development. iScience 23, 101838 (2020)

63. Lombaert, I. M. et al. Rescue of salivary gland function after stem cell transplantation in irradiated glands. PLOS ONE 3, e2063 (2008)

64. Emmerson, E. et al. SOX2 regulates acinar cell development in the salivary gland. eLife 6, e26620 (2017).

65. Maimets, M. et al. Long-term in vitro expansion of salivary gland stem cells driven by Wnt signals. Stem Cell Rep. 6, 150-162 (2016).

66. Aure, M. H., Konieczny, S. F. \& Ovitt, C. E. Salivary gland homeostasis is maintained through acinar cell self-duplication. Dev. Cell 33, 231-237 (2015)

67. Kwon, H. R. \& Larsen, M. The contribution of specific cell subpopulations to submandibular salivary gland branching morphogenesis. Curr. Opin. Genet. Dev. 32 47-54 (2015)

68. Pringle, $\mathrm{S}$. et al. Salivary gland stem cells age prematurely in primary Sjögren's syndrome. Arthritis Rheumatol 71, 133-142 (2019).

69. Wang, X. et al. Progenitor cell niche senescence reflects pathology of the parotid salivary gland in primary Sjögren's syndrome. Rheumatology 59 3003-3013 (2020).

70. Irvine, K. M. et al. Senescent human hepatocytes express a unique secretory phenotype and promote macrophage migration. World J. Gastroenterol. 20 17851-17862 (2014).

71. Hernandez-Segura, A., Nehme, J. \& Demaria, M. Hallmarks of cellular senescence. Trends Cell Biol. 28 436-453 (2018)

72. Gorgoulis, V. et al. Cellular senescence: defining a path forward. Cell 179, 813-827 (2019).

73. Cappelli, L. C. et al. Inflammatory arthritis and sicca syndrome induced by nivolumab and ipilimumab. Ann. Rheum. Dis. 76, 43-50 (2017).

74. Warner, B. M. et al. Sicca syndrome associated with immune checkpoint inhibitor therapy. Oncologist 24 , 1259-1269 (2019).
75. Tocut, M., Brenner, R. \& Zandman-Goddard, G Autoimmune phenomena and disease in cancer patients treated with immune checkpoint inhibitors. Autoimmun. Rev. 17, 610-616 (2018).

76. Michot, J. M. et al. Immune-related adverse events with immune checkpoint blockade: a comprehensive review. Eur. J. Cancer 54, 139-148 (2016).

77. Sharma, D. et al. Saliva microbiome in primary Sjögren's syndrome reveals distinct set of disease-associated microbes. Oral. Dis. 26, 295-301 (2020).

78. Zhou, S., Cai, Y., Wang, M., Yang, W. D. \& Duan, N. Oral microbial flora of patients with Sicca syndrome. Mol. Med. Rep. 18, 4895-4903 (2018).

79. Zhou, Z. et al. Molecular analysis of oral microflora in patients with primary Sjögren's syndrome by using high-throughput sequencing. PeerJ 6, e5649 (2018).

80 Sembler-Møller, M. L., Belstrøm, D., Locht, H. Enevold, C. \& Pedersen, A. M. L. Next-generation sequencing of whole saliva from patients with primary Sjögren's syndrome and non-Sjögren's sicca reveals comparable salivary microbiota. J. Oral. Microbiol. 11, 1660566 (2019)

81. Rusthen, S. et al. Dysbiotic salivary microbiota in dry mouth and primary Sjögren's syndrome patients. PLOS ONE 14, e0218319 (2019).

82. van der Meulen, T A et al. Dysbiosis of the buccal mucosa microbiome in primary Sjögren's syndrome patients. Rheumatology 57, 2225-2234 (2018).

83. Bodewes, I. L. A., Björk, A., Versnel, M. A. $\bar{d}$ Wahren-Herlenius, M. Innate immunity and nterferons in the pathogenesis of Sjögren's syndrome. Rheumatology https://doi.org/10.1093/rheumatology/ key360 (2019).

84. Garcia-Carrasco, M. et al. Hepatitis C virus infection in primary' Sjogren's syndrome: prevalence and clinical significance in a series of 90 patients. Ann. Rheum. Dis. 56, 173-175 (1997).

85. Brito-Zerón, P. et al. How hepatitis $C$ virus modifies the immunological profile of Sjögren syndrome: analysis of 783 patients. Arthritis Res. Ther. 17, 250 (2015)

86. Ramos-Casals, M. et al. Sjögren syndrome associated with hepatitis $C$ virus: a multicenter analysis of 137 cases. Medicine 84, 81-89 (2005)

87. Nakamura, $\mathrm{H}$. et al. Initial human T-cell leukemia virus type 1 infection of the salivary gland epithelial cells requires a biofilm-like structure. Virus Res. 269 197643 (2019)

88. Lima, C. M. et al. Association of sicca syndrome with proviral load and proinflammatory cytokines in HTLV-1 infection. J. Immunol. Res. 2016, 8402059 (2016).

89. Draborg, A., Izarzugaza, J. M. G. \& Houen, G. How compelling are the data for Epstein-Barr virus being a trigger for systemic lupus and other autoimmune diseases? Curr Opin. Rheumatol. 28, 398-404 (2016).

90. Sternbæk, L. et al. Increased antibody levels to stage-specific Epstein-Barr virus antigens in systemic autoimmune diseases reveal a common pathology. Scand. J. Clin. Lab. Invest. 79, 7-16 (2019).

91. Sanosyan, A. et al. Discrepancy of serological and molecular patterns of circulating Epstein-Barr virus reactivation in primary Sjögren's syndrome. Front. Immunol. 10, 1153 (2019).

92. Mariette, X., Gozlan, J., Clerc, D., Bisson, M. \& Morinet, F. Detection of Epstein-Barr virus DNA by in situ hybridization and polymerase chain reaction in salivary gland biopsy specimens from patients with sjögren's syndrome. Am. J. Med. 90, 286-294 (1991).

93. Croia, C. et al. Implication of Epstein-Barr virus infection in disease-specific autoreactive B cell activation in ectopic lymphoid structures of Sjögren's syndrome. Arthritis Rheumatol. 66, 2545-2557 (2014).

94. Xiao, J., Palefsky, J. M., Herrera, R., Berline, J. \& Tugizov, S. M. EBV BMRF-2 facilitates cell-to-cell spread of virus within polarized oral epithelial cells. Virology 388, 335-343 (2009).

95. Gallo, A. et al. Targeting the $\mathrm{Ca}^{2+}$ sensor STIM by exosomal transfer of Ebv-miR-BART13-3p is associated with Sjögren's syndrome. EBioMedicine 10 216-226 (2016).

96. Maślińska, M. The role of Epstein-Barr virus infection in primary Sjögren's syndrome. Curr. Opin. Rheumatol. 31, 475-483 (2019)

97. Smatti, M. K. et al. Viruses and autoimmunity: a review on the potential interaction and molecular mechanisms. Viruses 11, 762 (2019).

98. McClain, M. T. et al. Early events in lupus humoral autoimmunity suggest initiation through molecular mimicry. Nat. Med. 11, 85-89 (2005). 
99. Fischer, N. Infection-induced epigenetic changes and their impact on the pathogenesis of diseases. Semin. Immunopathol. 42, 127-130 (2020).

100. Li, H. et al. Identification of a Sjögren's syndrome susceptibility locus at OAS1 that influences isoform switching, protein expression, and responsiveness to type I interferons. PLoS Genet. 13, e1006820 (2017).

101. Lessard, C. J. et al. Variants at multiple loci implicated in both innate and adaptive immune responses are associated with Sjogren's syndrome. Nat. Genet. 45 1284-1292 (2013)

102. Liu, L. et al. Epithelial cells lining salivary gland ducts are early target cells of severe acute respiratory syndrome coronavirus infection in the upper respiratory tracts of rhesus macaques. J. Virol. $\mathbf{8 5}$, 4025-4030 (2011)

103. Xu, J., Li, Y., Gan, F., Du, Y. \& Yao, Y. Salivary glands: potential reservoirs for COVID-19 asymptomatic infection. J. Dent. Res. 99, 989 (2020).

104. Kamitaki, N. et al. Complement genes contribute sex-biased vulnerability in diverse disorders. Nature 582, 577-581 (2020).

105. Ghosh, S. \& Hayden, M. S. New regulators of NF-kB in inflammation. Nat. Rev. Immunol. 8 , 837-848 (2008)

106. Ewert, P. et al. Disruption of tight junction structure in salivary glands from Sjögren's syndrome patients is linked to proinflammatory cytokine exposure. Arthritis Rheum. 62, 1280-1289 (2010).

107. Nordmark, G. et al. Association of genes in the NF-kB pathway with antibody-positive primary Sjögren's syndrome. Scand. J. Immunol. 78, 447-454 (2013).

108. Ou, T.-T. et al. IkBa promoter polymorphisms in patients with primary Sjögren's syndrome. J. Clin. Immunol. 28, 440-444 (2008).

109. Sisto, M. et al. A failure of TNFAIP3 negative regulation maintains sustained NF-kB activation in Sjögren's syndrome. Histochem. Cell Biol. 135 615-625 (2011)

110. Wang, X. et al. Dysregulation of NF-kB in glandula epithelial cells results in Sjögren's-like features. PLOS ONE 13, e0200212 (2018).

111. Swanson, K. V., Deng, M. \& Ting, J. P. Y. The NLRP3 inflammasome: molecular activation and regulation to therapeutics. Nat. Rev. Immunol. 19, 477-489 (2019).

112. Chou, W.-C. et al. AIM2 in regulatory T cells restrains autoimmune diseases. Nature 591, 300-305 (2021).

113. Vakrakou, A. G., Svolaki, I. P., Evangelou, K., Gorgoulis, V. G. \& Manoussakis, M. N. Cell-autonomous epithelial activation of AIM2 (absent in melanoma-2) inflammasome by cytoplasmic DNA accumulations in primary Sjögren's syndrome. J. Autoimmun. 108 102381 (2020)

114. Vakrakou, A. G. et al. Systemic activation of NLRP3 inflammasome in patients with severe primary Sjögren's syndrome fueled by inflammagenic DNA accumulations. J. Autoimmun. 91, 23-33 (2018).

115. Baldini, C. et al. The P2X7 receptor-inflammasome complex has a role in modulating the inflammatory response in primary Sjögren's syndrome. J. Intern. Med. 274, 480-489 (2013).

116. Platanias, L. C. Mechanisms of type-I- and type-II-interferon-mediated signalling. Nat. Rev. Immunol. 5, 375-386 (2005).

117. Pestka, S., Langer, J. A., Zoon, K. C. \& Samuel, C. E. Interferons and their actions. Annu. Rev. Biochem. $\mathbf{5 6}$ 727-777 (1987)

118. Imgenberg-Kreuz, J. et al. Genome-wide DNA methylation analysis in multiple tissues in primary Sjögren's syndrome reveals regulatory effects at interferon-induced genes. Ann. Rheum. Dis. 75 2029-2036 (2016).

119. Nezos, A. et al. Type I and II interferon signatures in Sjogren's syndrome pathogenesis: contributions in distinct clinical phenotypes and Sjogren's related lymphomagenesis. J. Autoimmun. 63, 47-58 (2015).

120. Brkic, Z. et al. Prevalence of interferon type I signature in CD 14 monocytes of patients with Sjogren's syndrome and association with disease activity and BAFF gene expression. Ann. Rheum. Dis. 72, 728-735 (2013)

121. Rivière, E. et al. Salivary gland epithelial cells from patients with Sjögren's syndrome induce B-lymphocyte survival and activation. Ann. Rheum. Dis. 79 1468-1477 (2020)

122. Hall, J. C. et al. Precise probes of type II interferon activity define the origin of interferon signatures in target tissues in rheumatic diseases. Proc. Natl Acad. Sci. USA 109, 17609-17614 (2012).

123. Brewitz, A. et al. CD8 ${ }^{+}$T cells orchestrate pDC-XCR1 dendritic cell spatial and functional cooperativity to optimize priming. Immunity 46, 205-219 (2017).
124. Vanbervliet, B. et al. The inducible CXCR3 ligands control plasmacytoid dendritic cell responsiveness to the constitutive chemokine stromal cell-derived factor 1 (SDF-1)/CXCL12. J. Exp. Med. 198, 823-830 (2003)

125. Lövgren, T. et al. Induction of interferon- $\alpha$ by immune complexes or liposomes containing systemic lupus erythematosus autoantigen- and Sjögren's syndrome auto antigen-associated RNA. Arthritis Rheum. 54, 1917-1927 (2006).

126. Deshmukh, U. S., Nandula, S. R., Thimmalapura, P.-R., Scindia, Y. M. \& Bagavant, H. Activation of innate immune responses through Toll-like receptor 3 causes a rapid loss of salivary gland function. J. Oral. Pathol. Med. 38, 42-47 (2008).

127. Ittah, M. et al. Viruses induce high expression of BAFF by salivary gland epithelial cells through TLR- and type-I IFN-dependent and -independent pathways. Eur. J. Immunol. 38, 1058-1064 (2008).

128. Kyriakidis, N. C. et al. Toll-like receptor 3 stimulation promotes Ro52/TRIM21 synthesis and nuclear redistribution in salivary gland epithelial cells, partially via type I interferon pathway. Clin. Exp. Immunol. 178 548-560 (2014)

129. Mavragani, C. P. et al. Expression of long interspersed nuclear element 1 retroelements and induction of type I interferon in patients with systemic autoimmune disease. Arthritis Rheumatol. 68, 2686-2696 (2016).

130. Mavragani, C. P. et al. Defective regulation of L1 endogenous retroelements in primary Sjogren's syndrome and systemic lupus erythematosus: role of methylating enzymes. J. Autoimmun. 88, 75-82 (2018).

131. Zhao, K. et al. LINE1 contributes to autoimmunity through both RIG-I- and MDA5-mediated RNA sensing pathways. J. Autoimmun. 90, 105-115 (2018)

132. Hung, T. et al. The Ro60 autoantigen binds endogenous retroelements and regulates inflammatory gene expression. Science 350, 455-459 (2015).

133. Kong, H. J. et al. Cutting Edge: autoantigen Ro52 is an interferon inducible E3 ligase that ubiquitinates IRF-8 and enhances cytokine expression in macrophages. J. Immunol. 179, 26-30 (2007).

134. McEwan, W. A. et al. Intracellular antibody-bound pathogens stimulate immune signaling via the Fc receptor TRIM21. Nat. Immunol. 14, 327-336 (2013).

135. Higgs, R. et al. Self protection from anti-viral responses - Ro52 promotes degradation of the transcription factor IRF7 downstream of the viral Toll-like receptors. PLOS ONE 5, e11776 (2010).

136. Higgs, R. et al. The E3 ubiquitin ligase Ro52 negatively regulates IFN- $\beta$ production post-pathogen recognition by polyubiquitin-mediated degradation of IRF3. J. Immunol. 181, 1780-1786 (2008).

137. Lazzari, E. et al. TRIpartite Motif 21 (TRIM21) differentially regulates the stability of interferon regulatory factor 5 (IRF5) Isoforms. PLOS ONE 9, e103609 (2014)

138. Espinosa, A. et al. Loss of the lupus autoantigen Ro52/ Trim21 induces tissue inflammation and systemic autoimmunity by disregulating the IL-23-Th 17 pathway. J. Exp. Med. 206, 1661-1671 (2009).

139. Kunishita, Y. et al. TRIM21 dysfunction enhances aberrant B-cell differentiation in autoimmune pathogenesis. Front. Immunol. 11, 98 (2020).

140. Espinosa, A. et al. Anti-Ro52 autoantibodies from patients with Sjögren's syndrome inhibit the Ro52 E3 ligase activity by blocking the E3/E2 interface. J. Biol. Chem. 286, 36478-36491 (2011)

141. Monteith, A. J. et al. Defects in lysosomal maturation facilitate the activation of innate sensors in systemic lupus erythematosus. Proc. Natl Acad. Sci. USA 113, E2142-E2151 (2016).

142. Hillen, M. R. et al. Autoantigen TRIM21/Ro52 is expressed on the surface of antigen-presenting cells and its enhanced expression in Sjögren's syndrome is associated with $B$ cell hyperactivity and type $i$ interferon activity. RMD Open 6, e001184 (2020).

143. Ogawa, N., Ping, L., Zhenjun, L., Takada, Y. \& Sugai, S Involvement of the interferon- $\gamma$-induced

$T$ cell-attracting chemokines, interferon- $\gamma$-inducible 10-kd protein (CXCL10) and monokine induced by interferon- $\gamma$ (CXCL9), in the salivary gland lesions of patients with Sjögren's syndrome. Arthritis Rheum. 46, 2730-2741 (2002)

144. Ittah, M. et al. B cell-activating factor of the tumor necrosis factor family (BAFF) is expressed unde stimulation by interferon in salivary gland epithelial cells in primary Sjogren's syndrome. Arthritis Res. Ther. 8, R51 (2006).
145. Blokland, S. L. M. et al. Increased CCL25 and T helper cells expressing CCR9 in the salivary glands of patients with primary Sjögren's syndrome: potential new axis in lymphoid neogenesis. Arthritis Rheumatol. 69, 2038-2051 (2017).

146. Pontarini, E. et al. Unique expansion of IL-21+ Tfh and Tph cells under control of ICOS identifies Sjögren's syndrome with ectopic germinal centres and MALT lymphoma. Ann. Rheum. Dis. 79, 1588-1599 (2020).

147. Manoussakis, M. N. et al. Expression of B7 costimulatory molecules by salivary gland epithelial cells in patients with Sjögren's syndrome. Arthritis Rheum. 42, 229-239 (1999).

148. Dimitriou, I. D., Kapsogeorgou, E. K. Moutsopoulos, H. M. \& Manoussakis, M. N. CD40 on salivary gland epithelial cells: High constitutive expression by cultured cells from Sjögren's syndrome patients indicating their intrinsic activation. Clin. Exp. Immunol. 127, 386-392 (2002)

149. Kotenko, S. V. et al. IFN- $\lambda$ s mediate antiviral protection through a distinct class II cytokine receptor complex. Nat. Immunol. 4, 69-77 (2003)

150. Apostolou, E. \& Tzioufas, A. G. Type-III interferons in Sjögren's syndrome. Clin. Exp. Rheumatol. 38 (Suppl. 1), 245-252 (2020)

151. Apostolou, E. et al. Expression of type III interferons (IFN $\lambda$ s) and their receptor in Sjögren's syndrome. Clin. Exp. Immunol. 186, 304-312 (2016).

152. Mingueneau, M. et al. Cytometry by time-of-flight immunophenotyping identifies a blood Sjögren's signature correlating with disease activity and glandular inflammation. J. Allergy Clin. Immunol. 137 1809-1821.e12 (2016).

153. Kapsogeorgou, E. K., Moutsopoulos, H. M. \& Manoussakis, M. N. Functional expression of a costimulatory B7.2 (CD86) protein on human salivary gland epithelial cells that interacts with the $\mathrm{CD} 28$ receptor, but has reduced binding to CTLA4 J. Immunol. 166, 3107-3113 (2001).

154. Gong, Y.-Z. et al. Differentiation of follicular helper T cells by salivary gland epithelial cells in primary Sjögren's syndrome. J. Autoimmun. 51, 57-66 (2014).

155. Li, P. et al. p38 mitogen-activated protein kinase and nuclear factor-kB facilitate CD40-mediated salivary epithelial cell death. J. Rheumatol. 39, 1256-1264 (2012).

156. Jones, B. E., Maerz, M. D. \& Buckner, J. H. IL-6: a cytokine at the crossroads of autoimmunity. Curr. Opin. Immunol. 55, 9-14 (2018).

157. Fonseca, V. R. et al. Ratio of blood T follicular regulatory cells to $T$ follicular helper cells marks ectopic lymphoid structure formation while activated follicular helper T cells indicate disease activity in primary Sjögren's syndrome. Arthritis Rheumatol. 70 774-784 (2018)

158. Verstappen, G. M. et al. Is the T follicular regulatory/ T follicular helper cell ratio in blood a biomarker for ectopic lymphoid structure formation in Sjögren's syndrome? Arthritis Rheumatol. 70, 1354-1355 (2018)

159. Carrette, F \& Surh, C. D. IL-7 signaling and CD127 receptor regulation in the control of $T$ cell homeostasis. Semin. Immunol. 24, 209-217 (2012)

160. Bikker, A. et al. Increased expression of interleukin-7 in labial salivary glands of patients with primary Sjögren's syndrome correlates with increased inflammation. Arthritis Rheum. 62, 969-977 (2010).

161. Jin, J. O., Kawai, T., Cha, S. \& Yu, O. Interleukin-7 enhances the Th1 response to promote the development of Sjögren's syndrome-like autoimmune exocrinopathy in mice. Arthritis Rheum. 65 2132-2142 (2013).

162. Bikker, A. et al. Increased interleukin (IL)-7Ra expression in salivary glands of patients with primary Sjögren's syndrome is restricted to T cells and correlates with IL-7 expression, lymphocyte numbers and activity. Ann. Rheum. Dis. 71, 1027-1033 (2012).

163. Nocturne, G. \& Mariette, X. Sjogren Syndromeassociated lymphomas: an update on pathogenesis and management. Br. J. Haematol. 168, 317-327 (2015).

164. Daridon, C. et al. Aberrant expression of BAFF by $B$ lymphocytes infiltrating the salivary glands of patients with primary Sjögren's syndrome. Arthritis Rheum. 56, 1134-1144 (2007).

165. Batten, M. et al. BAFF mediates survival of peripheral immature B lymphocytes. J. Exp. Med. 192 1453-1465 (2000).

166. Mackay, F. \& Schneider, P. Cracking the BAFF code. Nat. Rev. Immunol. 9, 491-502 (2009). 
167. Lee, J. et al. JAK-1 inhibition suppresses interferon-induced BAFF production in human salivary gland: potential therapeutic strategy for primary Sjögren's syndrome. Arthritis Rheumatol. 70 , 2057-2066 (2018)

168. Thabet, Y. et al. Epigenetic dysregulation in salivary glands from patients with primary Sjögren's syndrome may be ascribed to infiltrating B cells. J. Autoimmun. 41, 175-181 (2013).

169. Haacke, E. A. et al. FcRL4+ B-cells in salivary glands of primary Sjögren's syndrome patients. J. Autoimmun. 81, 90-98 (2017).

170. Visser, A. et al. Repertoire analysis of B-cells located in striated ducts of salivary glands of patients With Sjögren's syndrome. Front. Immunol. 11, 1486 (2020).

171. Jourdan, M. et al. Characterization of human FCRL4-positive B cells. PLOS ONE 12, e0179793 (2017).

172. Verstappen, G. M. et al. Gene expression profiling of epithelium-associated FcRL4 ${ }^{+}$B cells in primary Sjögren's syndrome reveals a pathogenic signature. J. Autoimmun. 109, 102439 (2020).

173. Jackson, S. W. et al. B cell IFN- $\gamma$ receptor signaling promotes autoimmune germinal centers via cell-intrinsic induction of BCL-6. J. Exp. Med. 213 , 733-750 (2016)

174. Domeier, P. P. et al. IFN- $\gamma$ receptor and STAT signaling in B cells are central to spontaneous germinal center formation and autoimmunity. J. Exp. Med. 213, 715-732 (2016).

175. Vijayan, D. et al. IL-27 directly enhances germinal center $B$ cell activity and potentiates lupus in sanroque mice. J. Immunol. 197, 3008-3017 (2016).

176. Yoshimoto, T. et al. Induction of IgG2a class switching in B cells by IL-27. J. Immunol. 173, 2479-2485 (2004).

177. Jenks, S. A. et al. Distinct effector B cells induced by unregulated toll-like receptor 7 contribute to pathogenic responses in systemic lupus erythematosus. Immunity 49, 725-739.e6 (2018).

178. Wang, S. et al. IL-21 drives expansion and plasma cell differentiation of autoreactive $C D 11 \mathrm{C}^{\text {hi }}$ T-bet ${ }^{+} B$ cells in SLE. Nat. Commun. 9, 1758 (2018)

179. Sohn, H. W., Krueger, P. D., Davis, R. S. \& Pierce, S. K FCRL4 acts as an adaptive to innate molecular switch dampening BCR signaling and enhancing TLR signaling. Blood 118, 6332-6341 (2011).

180. Delli, K. et al. Towards personalised treatment in primary Sjögren's syndrome: baseline parotid histopathology predicts responsiveness to rituximab treatment. Ann. Rheum. Dis. 75, 1933-1938 (2016).

181. Cornec, D. et al. Blood and salivary-gland BAFF-driven $\mathrm{B}$-cell hyperactivity is associated to rituximab inefficacy in primary Sjögren's syndrome. J. Autoimmun. 67, 102-110 (2016).
182. Meijer, J. M. et al. Effectiveness of rituximab treatment in primary Sjögren's syndrome: a randomized, double-blind, placebo-controlled trial. Arthritis Rheum. 62, 960-968 (2010).

183. Devauchelle-Pensec, V. et al. Treatment of primary Sjogren syndrome with rituximab: a randomized trial. Ann. Intern. Med. 160, 233-242 (2014).

184. Bowman, S. J. et al. Randomized controlled trial of rituximab and cost-effectiveness analysis in treating fatigue and oral dryness in primary Sjögren's syndrome. Arthritis Rheumatol. 69, 1440-1450 (2017).

185. Ehrhardt, G. R. A. et al. Discriminating gene expression profiles of memory B cell subpopulations. J. Exp. Med. 205, 1807-1817 (2008).

186. Wherry, J. et al. Viral infection expression is required to control chronic intrinsic T-bet - cutting edge: B cell. J. Immunol. 197, 1017-1022 (2016).

187. Álvarez-Prado, Á. F. et al. A broad atlas of somatic hypermutation allows prediction of activation-induced deaminase targets. J. Exp. Med. 215, 761-771 (2018).

188. Bende, R. J et al. Salivary gland MALT lymphomas of Sjögren's syndrome patients in majority express rheumatoid factors affinity-selected for IgG. Arthritis Rheumatol. 72, 1330-1340 (2020).

189. Zucca, E. \& Bertoni, F. The spectrum of MALT lymphoma at different sites: biological and therapeutic relevance. Blood 127, 2082-2092 (2016)

190. Bende, R. J. et al. Among B cell non-Hodgkin's lymphomas, MALT lymphomas express a unique antibody repertoire with frequent rheumatoid factor reactivity. J. Exp. Med. 201, 1229-1241 (2005).

191. Singh, M. et al. Lymphoma driver mutations in the pathogenic evolution of an iconic human autoantibody. Cell 180, 878-894.e19 (2020).

192. Saadoun, D. et al. Expansion of autoreactive unresponsive $\mathrm{CD} 21^{\text {-low }} \mathrm{B}$ cells in sjögren's syndrome-associated lymphoproliferation. Arthritis Rheum. 65, 1085-1096 (2013).

193. Glauzy, S. et al. Accumulation of antigen-driven lymphoproliferations in complement receptor $2 / \mathrm{CD} 21^{\text {-llow }} \mathrm{B}$ cells from patients with Sjögren's syndrome. Arthritis Rheumatol. 70, 298-307 (2018).

194. Jenks, S. A., Cashman, K. S., Woodruff, M. C., Lee, F. E. $\&$ Sanz, I. Extrafollicular responses in humans and SLE. Immunol. Rev. 288, 136-148 (2019).

195. Bende, R. J. et al. Stereotypic rheumatoid factors that are frequently expressed in mucosa-associated lymphoid tissue-type lymphomas are rare in the labial salivary glands of patients with Sjögren's syndrome. Arthritis Rheumatol. 67, 1074-1083 (2015).

196. Visser, A. et al. Acquisition of $\mathrm{N}$-glycosylation sites in immunoglobulin heavy chain genes during local expansion in parotid salivary glands of primary Sjögren patients. Front. Immunol. 9, 491 (2018).
197. Lau, C. M. et al. RNA-associated autoantigens activate $B$ cells by combined $B$ cell antigen receptor/Toll-like receptor 7 engagement. J. Exp. Med. 202, 1171-1177 (2005).

198. Potter, K. N., Li, Y., Mageed, R. A., Jefferis, R. \& Capra, J. D. Molecular characterization of the $\mathrm{V}_{\mathrm{H}} 1$-specific variable region determinants recognized by anti-idiotypic monoclonal antibodies $\mathrm{G} 6$ and $\mathrm{G} 8$. Scand. J. Immunol. 50, 14-20 (1999).

199. Nocturne, G. et al. Germline and somatic genetic variations of TNFAIP3 in lymphoma complicating primary Sjögren's syndrome. Blood 122, 4068-4076 (2013).

200. Gueiros, L. A. et al. World workshop on oral medicine VII: immunobiologics for salivary gland disease in Sjögren's syndrome: a systematic review. Oral. Dis. 25, 102-110 (2019).

201. Pringle, S. et al. Small-molecule inhibitors and the salivary gland epithelium in Sjögren's syndrome. Expert Opin. Investig. Drugs 28, 605-616 (2019).

202. Amor, C. et al. Senolytic CAR T cells reverse senescence-associated pathologies. Nature 583, 127 (2020).

203. Pringle, S. et al. Lack of conventional acinar cells in parotid salivary gland of patient taking an anti-PD-L1 immune checkpoint inhibitor. Front. Oncol. 10, 420 (2020).

204. Pringle, S., Wang, X., Vissink, A., Bootsma, H. \& Kroese, F. G. M. Checkpoint inhibition-induced sicca: a type II interferonopathy? Clin. Exp. Rheumatol. 126, 253-260 (2020).

Acknowledgements

The work of the authors is supported by a Dutch Arthritis Society (ReumaNL) Long Term Project Grant (LLP-29). The authors would like to thank M. S. van Ginkel and B. van der Vegt for providing the histology images.

\section{Author contributions}

G.M.V. and S.P. researched data for the article and wrote the article. All authors provided substantial contribution to the discussion of content. H.B. and F.G.M.K. reviewed and/or edited the manuscript before submission.

\section{Competing interests}

The authors declare no competing interests.

Peer review information

Nature Reviews Rheumatology thanks A. Tzioufas, G. Nocturne, B. Fisher and the other, anonymous, reviewer(s) for their contribution to the peer review of this work.

Publisher's note

Springer Nature remains neutral with regard to jurisdictional claims in published maps and institutional affiliations.

(c) Springer Nature Limited 2021 